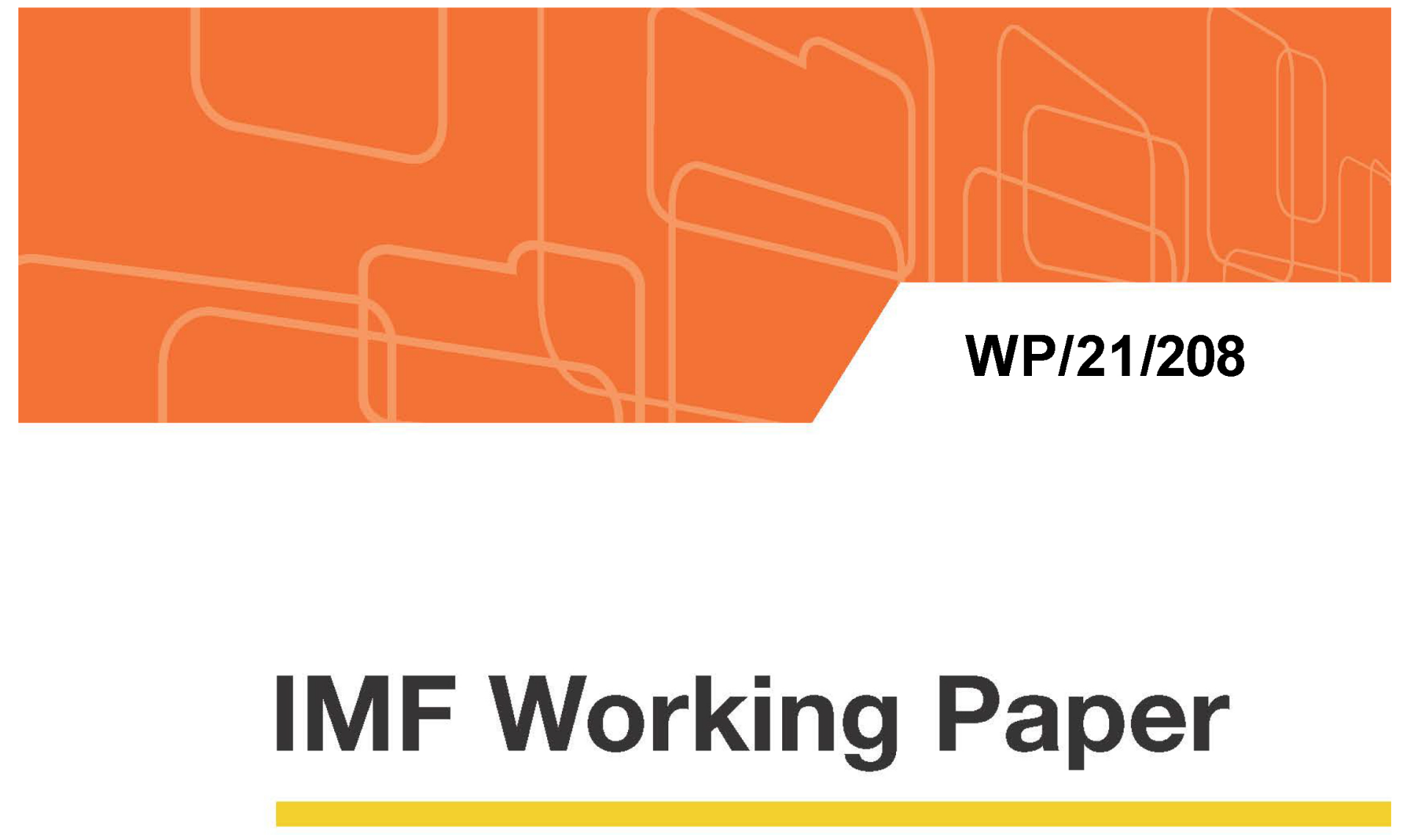

\title{
Endogenous Growth, Downward Wage Rigidities and Optimal Inflation
}

Mirko Abbritti, Agostino Consolo and Sebastian Weber

IMF Working Papers describe research in progress by the author(s) and are published to elicit comments and to encourage debate. The views expressed in IMF Working Papers are those of the author(s) and do not necessarily represent the views of the IMF, its Executive Board, or IMF management.

$$
\text { I N T E R N A T I O N A L M O NETAR Y FU N D }
$$




\title{
IMF Working Paper
}

European Department

\section{Endogenous Growth, Downward Wage Rigidities and Optimal Inflation Prepared by Mirko Abbritti, Agostino Consolo and Sebastian Weber} Authorized for distribution by Jeffrey R. Franks

August 2021

\begin{abstract}
IMF Working Papers describe research in progress by the author(s) and are published to elicit comments and to encourage debate. The views expressed in IMF Working Papers are those of the author(s) and do not necessarily represent the views of the IMF, its Executive Board, or IMF management.
\end{abstract}

\begin{abstract}
Standard New Keynesian (NK) models feature an optimal inflation target well below two percent, limited welfare losses from business cycle fluctuations and long-term monetary neutrality. We develop a NK framework with labour market frictions, endogenous productivity and downward wage rigidity (DWR) which challenges these results. The model features a non-vertical long-run Phillips curve between inflation and unemployment and a trade-off between price distortions and output hysteresis that change the welfare-maximizing inflation level. For a plausible set of parameters, the optimal inflation target is in excess of two percent, a target value commonly used across central banks. Deviations from the optimal target carry welfare costs multiple times higher than in traditional NK models. The main reason is that endogenous growth and DWR generate asymmetric and hysteresis effects on unemployment and output. Price level targeting or a Taylor-rule responding to the unemployment rate can handle better the asymmetric and hysteresis effects in our model and deliver significant welfare gains. Our results are robust to the inclusion of the effective lower bound on the monetary policy interest rate.
\end{abstract}

JEL Classification Numbers: E24, E3, E5, O41, J64

Keywords: Endogenous Growth, Monetary Policy, Optimal Inflation Target, Downward Wage Rigidity, Monetary Policy Invariance Hypothesis, Zero Lower Bound.

Author's E-Mail Address: Mirko.Abbritti@unipg.it, Agostino.Consolo@ecb.europa.eu, SWeber@imf.org 


\title{
Endogenous growth, downward wage rigidities and optimal inflation*
}

\author{
Mirko Abbritti, ${ }^{\dagger}$ Agostino Consolo ${ }^{\ddagger}$ and Sebastian Weber ${ }^{\S}$
}

\begin{abstract}
Standard New Keynesian (NK) models feature an optimal inflation target well below two percent, limited welfare losses from business cycle fluctuations and long-term monetary neutrality. We develop a NK framework with labour market frictions, endogenous productivity and downward wage rigidity (DWR) which challenges these results. The model features a non-vertical long-run Phillips curve between inflation and unemployment and a trade-off between price distortions and output hysteresis that change the welfare-maximizing inflation level. For a plausible set of parameters, the optimal inflation target is in excess of two percent, a target value commonly used across central banks. Deviations from the optimal target carry welfare costs multiple times higher than in traditional NK models. The main reason is that endogenous growth and DWR generate asymmetric and hysteresis effects on unemployment and output. Price level targeting or a Taylor-rule responding to the unemployment rate can handle better the asymmetric and hysteresis effects in our model and deliver significant welfare gains. Our results are robust to the inclusion of the effective lower bound on the monetary policy interest rate.

Keywords: Endogenous Growth, Monetary Policy, Optimal Inflation Target, Downward Wage Rigidity, Monetary Policy Invariance Hypothesis, Zero Lower Bound.
\end{abstract}

JEL Classification: E24, E3, E5, O41, J64

${ }^{*}$ We are grateful to Robert Anderton, Philip Lane, Michele Lenza, Wolfgang Modery, Roberto Motto, Fabio Panetta, Frank Smets, Ignacio Campomanes, Antonio Moreno and seminar participants at the ECB, IMF and University of Navarra for helpful comments. We are also especially grateful to Tom Holden for his help with the DynareOBC toolkit and to Stephan Fahr for many fruitful discussions over the years. The views expressed in this paper are those of the authors and do not necessarily represent those of the ECB or the IMF

${ }^{\dagger}$ University of Perugia and Navarra Center for International Development, ICS, University of Navarra, Email: mirko.abbritti@unipg.it

‡European Central Bank, Email: agostino.consolo@ecb.europa.eu

§International Monetary Fund, Email: sweber@imf.org 


\section{Introduction}

The monetary policy framework and the definition of price stability prevailing in modern central banking hinge on the seminal contribution from Friedman (1968) that crystallized two main propositions: (i) there is a natural level of the unemployment rate that is invariant to inflation and (ii) monetary policy has no long-run effects on the real economy. ${ }^{1}$ This view, described by Blanchard (2018) and Hall and Sargent (2018) as the monetary policy invariance hypothesis, has been challenged by the events following the Global Financial Crisis (Yellen, 2016), which appear to have shifted many advanced economies' output to a permanently lower growth trajectory than the one prevailing before 2007 (see Figure 1, panel (a)).

\section{Figure 1: Hysteresis in output and unemployment in the euro area}
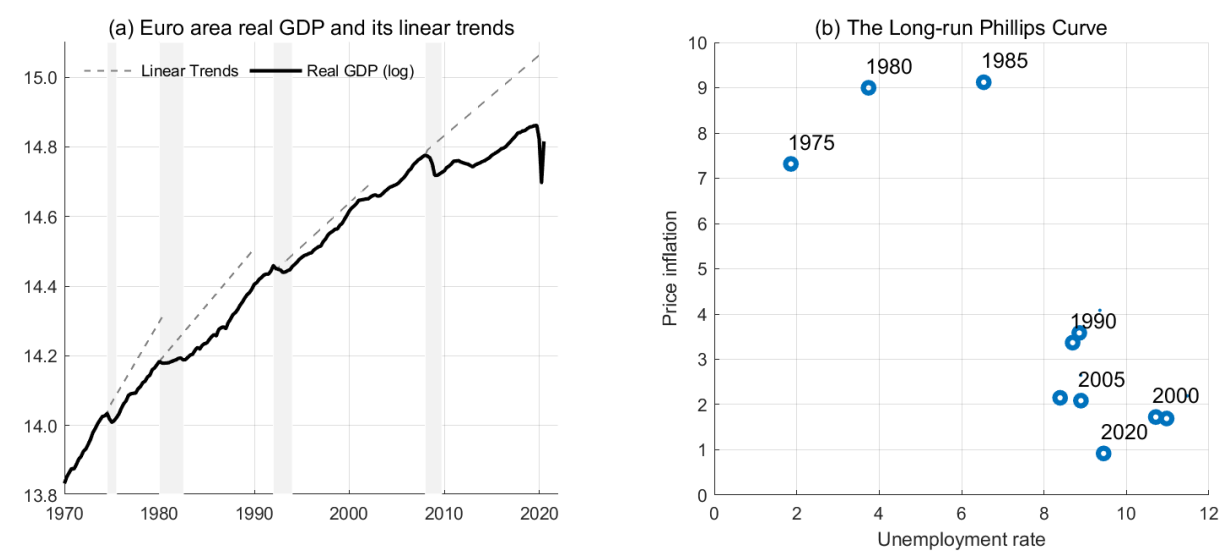

Panel(a): Data are in logs. Shaded areas are euro area recessions as identified by the CEPR business cycle dating committee. Dashed lines refer to linear trends prevailing before each respective recession. Source: Eurostat Panel(b): Each data point corresponds to the 5-year historical average of inflation and unemployment. Source: ECB Area Wide database

This paper studies monetary policy in a dynamic stochastic general equilibrium (DSGE) model with search and matching unemployment featuring endogenous growth and downward wage rigidity. The model generates five key findings that are of relevance for the conduct of monetary policy in a low-growth economy, not captured by traditional models with exogenous growth. First, the model gives rise to asymmetric business cycle dynamics and hysteresis effects on output and unemployment that resemble the plucking theory of the business cycle. Second, the model embeds a long-run trade-off between output growth and inflation (i.e., a non-vertical Phillips curve) which depends on the central bank's inflation target. Third, consumptionequivalent welfare losses are a multiple of those associated with traditional models, because endogenous growth magnifies the trade-off between price distortions and output hysteresis. Fourth, the inflation target that optimally balances this trade-off is consistently above 2 percent. Fifth, a price level targeting or a Taylor-rule with

\footnotetext{
${ }^{1}$ The 17-page speech given to the American Economic Association meeting in December 1967 marked a turning point in the history of macroeconomic research (Mankiw and Reis, 2018). See also Phelps (1967).
} 
sufficient weight on the unemployment rate significantly lower welfare losses and imply a lower welfare-optimising inflation target.

The mechanism underlying our findings rely on the interplay of an endogenous growth channel and downward wage rigidities in a New Keynesian (NK) model with search and matching frictions that generate unemployment.

The endogenous growth channel enriches a standard NK model with important supply-side features on the determinants of long-run growth. We follow Anzoategui et al. (2019), Kung and Schmid (2015) and introduce endogenous growth in the model via an innovation sector that conducts $R \& D$ expenditure to expand the stock of intangibles and the variety of patented goods in the economy. In this setting, large negative demand shocks (e.g. risk premium shocks) reduce firms' profits and R\&D investment, which in turn reduce the process of intangible capital accumulation, which is ultimately the engine of growth. Through this channel, large temporary shocks have the potential to generate permanent effects on TFP and output that resemble the hysteresis effects of the Global Financial Crisis (Cerra and Saxena, 2008; Benigno and Fornaro, 2018; Acharya et al., 2021; Anzoategui et al., 2019; Abbritti and Weber, 2019).

The inclusion of DWR in a frictional labour market generates large asymmetries in the unemployment and output response to positive and negative demand shocks. Following Schmitt-Grohé and Uribe (2013), Dupraz et al. (2019) and Acharya et al. (2021), we model downward wage rigidities (DWR) as an occasionally binding constraint on nominal wage adjustment. ${ }^{2}$ Following positive demand shocks, the increase in nominal wages limits hiring and job creation. When following negative demand shocks, instead, the presence of DWR constrains the adjustment of nominal wages, while prices decrease relatively fast. As a result, real wages increase during the downturn, strongly amplifying the negative effects on employment, investment and output. In a search and matching framework, this leads to higher unemployment duration. For this reason, DWR generates asymmetric business cycle fluctuations that resemble those of the plucking theory in which the unemployment rate jumps at the start of a recession and slowly declines during a recovery (Friedman, 1993; Benigno and Ricci, 2011; Abbritti and Fahr, 2013; Dupraz et al., 2019).

When combined, endogenous productivity and DWR imply asymmetric and longterm effects from business cycles shocks. Large temporary shocks affect not only the long-run level of output and TFP, but also the corresponding average growth rates of the economy, because the hysteresis effect of negative shocks is larger than that of positive shocks. For this reason, the monetary policy invariance hypothesis does not hold in our model as the long-run level of unemployment and output growth depend on the monetary policy strategy and, hence, the inflation target adopted by the central bank.

\footnotetext{
${ }^{2}$ The introduction of downward wage rigidities is underpinned by empirical evidence, for instance based on micro empirical studies for the euro area and the US economy (Dickens et al., 2007; Grigsby et al., 2021).
} 
Deviations from the optimal inflation target, which we find to be above 2 percent, carry non-trivial welfare costs amidst the non-neutrality implied by accounting for endogenous growth and downward wage rigidity in an otherwise standard NK model with search and matching frictions. In our model, increasing the inflation target has two main effects. First, it increases the distortions related to price and wage rigidity. Second, it reduces the probability of hitting the occasionally binding wage constraint, and therefore reduces the costs related to DWR. From a welfare perspective, there is thus an optimal rate of inflation which balances the costs of price distortions on one side and hysteresis effects on output and unemployment on the other. This trade-off is a consequence of the presence of DWR in a NK model with unemployment. The endogenous growth channel enriches this trade-off along two important dimensions: (i) recessions have long-term effects on the level of output, and (ii) the costs associated with the lower bound on wages are no longer paid infrequently, but they persist in the future after an adverse shock hits the economy. This amplifies the welfare repercussions of deviating from the optimal target.

We verify the robustness of our results to several changes in the assumptions underlying the calibration of key parameters of the economy such as the volatility of the shock processes, the pricing scheme (Rotemberg vs. Calvo), the tightness of the wage floor, the endogenous TFP process and the hiring and investment adjustment costs. We consistently find large welfare costs associated with deviating from the optimal inflation target, which remains throughout above 2 percent. Our results also show that the need for a high inflation target could be intensified in a low-growth, low-inflation and high-volatility environment, as the constraint on downward wage rigidity becomes more binding in such situations. This observation seems particularly relevant given the recent experience of many advanced economies. ${ }^{3}$

Finally, we complement our analysis with two extensions. In the first extension we analyse the effects of adding the zero lower bound (ZLB) on the monetary policy rate, which follows a standard Taylor rule. We find that the introduction of the effective lower bound on the nominal interest rate (Bernanke, 2017; Krugman, 1998; Eggertsson and Woodford, 2003) leaves our main results unaffected. The welfareoptimising inflation target slightly increases, but it remains very close to the one in the baseline model. In the second extension, we compare the performances of alternative monetary policy strategies. We find both, price-level targeting and a simple monetary policy rule that responds to the unemployment rate are better suited for a model economy which features asymmetry and hysteresis than a standard Taylor rule. The history-dependence feature of price-level targeting leads to lower welfare losses. The simple rule with the unemployment rate is welfare improving

\footnotetext{
${ }^{3}$ At the start of the Economic and Monetary Union, long-term output growth and average price inflation were about $2.2 \%$ and $2.0 \%$, respectively. This was the economic environment prevailing during the first review of the ECB monetary policy strategy in 2003, which led to the numerical definition of the ECB price stability to close but below $2 \%$. More recently, the long-term averages for output growth and inflation have almost halved (to 1.0\% and 1.3\%, respectively) and such changes have been particularly visible after 2007 (See Table 10 in the annex).
} 
because the unemployment rate captures most of the asymmetric features of the business cycle and translates it into a model-consistent policy response. In this context, we find that welfare losses would be almost halved and the optimal inflation rate be close to 2.5 percent - much closer to the inflation target adopted by most advanced economies. Shifting to such strategies would lead to significant welfare gains and, in our framework, is superior to an average inflation targeting regime.

Our model and findings are related to three broad strands of the literature studying endogenous growth, downward wage rigidity, and optimal inflation targeting in New Keynesian models.

Recent works have used the endogenous productivity mechanism to explain the persistence of the propagation mechanism from the Global Financial Crisis, which has led to long slumps (Hall, 2011) and has further exacerbated the secular trend in economic growth (Bianchi et al., 2019). Anzoategui et al. (2019) provide evidence for the US economy that productivity-enhancing investment such as R\&D is highly procyclical and find that part of the long-term productivity slowdown following the Great Recession has been driven by a reduction in R\&D investment and a lower adoption rate of new technologies. For European companies, Ferrando and Preuss (2018) find that investment in intangible assets is also highly procyclical as it depends on firms' internal finance and firms' size. ${ }^{4}$ Moran and Queralto (2018) study the link between monetary policy and endogenous TFP dynamics in a NK model, showing that the ZLB on interest rates can lead to large permanent TFP losses. Garga and Singh (2020) analyse optimal monetary policy in a NK model featuring endogenous growth and the ZLB on interest rates, finding that at the ZLB a strict inflation targeting rule is suboptimal and leads to output hysteresis, defined as a permanent loss in potential output.

Starting with Tobin (1972) the presence of downward wage rigidity provides a rationale for a positive inflation buffer, which can support relative wage adjustment without incurring significant social costs in terms of unemployment and discouraging workers. Recent research shows that downward wage stickiness can generate large business cycle asymmetries (Akerlof et al., 1996). For instance, Benigno and Ricci (2011) provide a theoretical foundation for a highly nonlinear relationship for the long-run trade-off between average wage inflation and output gap: the trade-off is virtually inexistent at high inflation rates, while - due to DWR - it becomes relevant in a low inflation environment. Abbritti and Fahr (2013) demonstrate that the presence of downward wage rigidities strongly improves the fit of an otherwise standard NK model with labour market frictions to the observed pattern of asymmetries of a number of OECD countries. Dupraz et al. (2019) embed downward wage rigidities

\footnotetext{
${ }^{4}$ Over the business cycle, larger firms substitute internal and external finance depending on pricing conditions - as they are less affected by financial constraints and collateral requirements while smaller firms use external equity and debt financing in a procyclical manner (Begenau and Salomao, 2018). Given the prevalence of small- and medium-size firms in the euro area, financial constraints play an important role on the procyclicality of $\mathrm{R} \& \mathrm{D}$ investment and on the long-term consequences for productivity growth.
} 
in a search model of the labour market to develop a microfounded plucking model of the business cycle, whereby economic contractions are followed by expansions of a similar amplitude, while the amplitude of contractions are not related to the previous expansion. Most of this literature has focused on downward wage rigidity and the optimal inflation target in models with exogenous trend growth. Therefore, the asymmetric feature of downward wage rigidity had limited propagation mechanisms for long-term growth. In our model the endogenous growth channel is critical for the determination of the long run Phillips curve and the welfare implications.

Finally, our work is related to the extensive literature on the optimal rate of inflation in NK models (see e.g. Schmitt-Grohé and Uribe (2010), Kim and Ruge-Murcia (2009), Coibion et al. (2012), Ascari and Sbordone (2014), Amano and Gnocchi (2020), Andrade et al. (2019, 2021)). Most of these studies show that even in the presence of the ZLB, the optimal inflation target is relatively low, typically below 2 percent. ${ }^{5}$ The reason is that ZLB episodes are infrequent and welfare-related costs are large but short lived in models with exogenous growth dynamics. Price and wage distortions created by higher inflation targets, instead, are small but paid in each period. As shown by Andrade et al. (2019, 2021), the case for a higher inflation target gets stronger once one takes into account the decline in the natural rate of interest recently experienced by most advanced economies.

The remainder of the paper is structured as follows: Section 2 lays out the New Keynesian model with endogenous growth and downward wage rigidity. Section 3 describes the calibration strategy and solution method for the endogenous growth model and for a benchmark model with exogenous growth. Section 4 analyzes how the introduction of endogenous growth (i) allows for persistent and even permanent effects in response to temporary shocks, and (ii) affects monetary policy effectiveness and the slope of the long run Phillips curve. Section 5 describes a welfare metric that accounts for long-term growth, which is then used to derive the optimal inflation target, and to analyze the implied welfare losses under different scenarios. Section 6 discusses two extensions of our model. Section 7 concludes.

\section{The Model}

In this section we set up a New Keynesian (NK) model which combines nominal price stickyness á la Rotemberg (1982) with three additional ingredients: (1) search and matching frictions in the labour market, which give rise to involuntary unemploment; (2) endogenous TFP growth through R\&D investment and innovation; and

\footnotetext{
${ }^{5}$ There are a few exceptions. For instance, Adam and Weber (2019) find that the optimal inflation rate ranges between 1 and 3 percent in a model with firm heterogeneity. A higher firm turnover would call for a higher optimal inflation rate to grease relative productivity adjustments among new and old firms. Blanco (Forthcoming) studies optimal inflation in a quantitative menu cost model with a zero lower bound on interest rates and find that the optimal inflation target is larger than what is typically found in models with time-dependent pricing.
} 
(3) downward wage rigidities in the form of an occasionally binding constraint on wage inflation.

\subsection{The labour market}

The labour market is characterized by search frictions. Let $m_{t}$ denote the newly formed firm-worker matches in the labour market. Their number depends on the measure of vacancies, $v_{t}$, and job seekers, $u_{t}$, following a constant return to scale matching technology:

$$
m_{t}=\bar{m} u_{t}^{\zeta} v_{t}^{1-\zeta}
$$

where $\bar{m}>0, \zeta \epsilon(0,1)$ and $u_{t}=1-(1-\rho) N_{t-1}$ is the number of searching workers at the beginning of period $t . \rho$ is the fraction of employment relationships that is destroyed in each period. The probability for the firm to fill an open vacancy is

$$
q_{t}=\frac{m_{t}}{v_{t}}=\bar{m} \theta_{t}^{-\zeta}
$$

where $\theta_{t}=\frac{v_{t}}{u_{t}}$ denotes labor market tightness. The probability that a worker looking for a job is matched with an open vacancy is

$$
f_{t}=\frac{m_{t}}{u_{t}}=\theta_{t} q\left(\theta_{t}\right)
$$

For future reference, let us also define (after-hiring) unemployment as the fraction of searching workers that remain unemployed after hiring takes place:

$$
u r_{t}=1-N_{t}
$$

\subsection{Households}

Each household is made up of a continuum of members represented by the unit interval. The representative household maximizes a standard lifetime utility

$$
\mathbb{E}_{0} \sum_{t=0}^{\infty} \beta^{t} \log C_{t}
$$

where $C_{t}$ is a Dixit-Stiglitz consumption bundle with elasticity of substitution $\epsilon$ and $\beta$ is the subjective discount factor. Households own all firms in the economy and face the following per period budget constraint:

$$
C_{t}+I_{t}+\frac{B_{t}}{P_{t}}=w_{t} N_{t}+r_{K t} z_{t} k_{t}+b_{t}\left(1-N_{t}\right)+\frac{R_{t-1} \varrho_{t-1} B_{t-1}}{P_{t}}+D_{t}
$$

where $I_{t}$ denotes investment in the physical capital stock, $P_{t}$ is the aggregate price level and $R_{t}$ is the gross nominal interest rate of the nominal bond $B_{t}$. $z_{t}$ denotes 
the utilization rate of capital. ${ }^{6}$ Total household income is the sum of the real wage income earned by employed family members $w_{t} N_{t}$, the benefits earned by the unemployed $b_{t}\left(1-N_{t}\right)$, the return on capital $r_{K t} z_{t} k_{t}$ and the family share of aggregate profits from retailers and matched firms $D_{t} \cdot{ }^{7} \varrho_{t}$ is a risk premium á la Smets and Wouters (2007), which will allow us to gauge the implications of financial shocks without explicitly modelling financial frictions.

The number of employed family members, $N_{t}$, is given by the number of continuing relationships, $(1-\rho) N_{t-1}$, plus the number of new hires, $m_{t}=f_{t} u_{t}$, which are immediately operative:

$$
N_{t}=(1-\rho) N_{t-1}+f_{t} u_{t}
$$

The law of motion of physical capital is:

$$
k_{t+1}=\left(1-\delta_{K}\left(z_{t}\right)\right) k_{t}+\left[1-\frac{\Theta_{I}}{2}\left(\frac{I_{t}}{I_{t-1}}-g\right)^{2}\right] I_{t}
$$

where $\frac{\Theta_{I}}{2}\left(\frac{I_{t}}{I_{t-1}}-g\right)^{2}$ captures convex costs in physical investment, $\Theta_{I}>0$ is a scale parameter and $g$ is the steady state growth rate of the economy. The depreciation rate is convex in the capital utilization rate: $\delta_{K}\left(z_{t}\right)=\delta z_{t}^{\phi_{k}}$.

Let us denote by $\lambda_{t}$ the multiplier associated with the budget constraint and by $\pi_{t}=\frac{P_{t}}{P_{t-1}}$ the gross inflation rate. The solution to the maximization problem of the household leads to the following first order conditions:

$$
\begin{aligned}
\lambda_{t}= & \frac{1}{C_{t}} \\
1= & \beta \mathbb{E}_{t} \frac{\lambda_{t+1}}{\lambda_{t}} \frac{R_{t}}{\pi_{t+1}} \varrho_{t} \\
1= & Q_{K t}\left\{\left(1-\frac{\Theta_{I}}{2}\left(\frac{I_{t}}{I_{t-1}}-g\right)^{2}\right)-\Theta_{I}\left(\frac{I_{t}}{I_{t-1}}-g\right) \frac{I_{t}}{I_{t-1}}\right\} \\
& +\mathbb{E}_{t} \beta \frac{\lambda_{t+1}}{\lambda_{t}} Q_{K t+1}\left\{\left[\Theta_{I}\left(\frac{I_{t+1}}{I_{t}}-g\right)\left(\frac{I_{t+1}}{I_{t}}\right)^{2}\right]\right\} \\
Q_{K t}= & \mathbb{E}_{t} \beta \frac{\lambda_{t+1}}{\lambda_{t}}\left\{r_{K t+1} z_{t+1}+Q_{K t+1}\left(1-\delta_{K}\left(z_{t+1}\right)\right)\right\} \\
r_{K t}= & Q_{K t} \delta_{K}^{\prime}\left(z_{t}\right)
\end{aligned}
$$

where $Q_{K t}$ is the Tobin's Q. For future reference, let us also define the value of employment for the family, $V_{t}^{E}$, as

$$
V_{t}^{E}=w_{t}-b_{t}+\beta(1-\rho) \mathbb{E}_{t} \frac{\lambda_{t+1}}{\lambda_{t}}\left\{\left(1-f_{t+1}\right) V_{t+1}^{E}\right\}
$$

\footnotetext{
${ }^{6}$ As in Anzoategui et al. (2019), we allow for variable capital utilization intensity so as not to mistakenly attribute all high frequency variation in the Solow residual to endogenous technology.

${ }^{7}$ Notice that when productivity grows along the balanced growth path, also the unemployment benefits grow at the same rate: $b_{t}=b \Psi_{t}$, where $\Psi_{t}$ is a scaling factor which ensures the existence of a balanced growth path. This guarantees that unemployment benefits are constant along the balanced growth path.
} 
The net value of an additional employed worker in the family is the wage net of unemployment benefits, plus the expected continuation value from the employment relationship.

\subsection{Production}

There are four sectors in the economy. Firms in the intermediate good sector produce the intermediate homogeneous good in competitive markets using labour and capital. This output is bought by specialized patent producers who own the exclusive right to produce their patented variety. These specialized patented goods are then sold to retailers. Retailers assemble different specialized goods into their differentiated goods which are then sold to households. New patents are created by innovation through $R \& D$ in the innovation sector.

\subsubsection{Final good and retailers}

There is a measure one of monopolistic retailers indexed by $i$ on the unit interval, each of them producing one differentiated product. These differentiated goods are then assembled to become the final composite good:

$$
Y_{t}=\left[\int_{0}^{1}\left(Y_{t}^{i}\right)^{\frac{\epsilon-1}{\epsilon}} d i\right]^{\frac{\epsilon}{\epsilon-1}}
$$

where $\epsilon$ represents the elasticity of substitution between retail goods. Therefore, the demand function for each retailer for its product is:

$$
Y_{t}^{i}=\left(\frac{P_{t}^{i}}{P_{t}}\right)^{-\epsilon} Y_{t}
$$

where $P_{t}^{i}$ is the price of the final good $i$ and the aggregate price index is $P_{t}=$ $\left[\int_{0}^{1}\left(P_{t}^{i}\right)^{1-\epsilon} d i\right]^{\frac{1}{1-\epsilon}}$

Retailers produce the final retail good using a composite of specialized goods $Y_{S, t}^{j}$, according to the following CES production function:

$$
Y_{t}^{i}=\left[\int_{0}^{Z_{t}}\left(Y_{S, t}^{j}\right)^{v} d j\right]^{\frac{1}{v}}
$$

where $Z_{t}$ is the number of patents in use at date $t, Y_{S, t}^{j}$ is the quantity of specialized good $j$ and $p_{S, t}^{j}$ is the corresponding real price. $v<1$ governs the elasticity of substitution between patents. 
We introduce nominal rigidities for retailers assuming firms face Rotemberg-style quadratic costs of adjusting prices:

$$
\Gamma_{P t}^{i}=\frac{\psi}{2}\left(\pi_{t}^{i}-\pi_{t}^{R}\right)^{2}
$$

where $\pi_{t}^{i}=\frac{P_{t}^{i}}{P_{t-1}^{i}}$ and $\pi_{t}^{R}$ is the inflation rate used as reference for the adjustment costs. If $\pi_{t}^{R}=\pi^{*}$ adjustment costs are 0 when inflation is equal to the inflation target $\pi^{*}$; for $\pi_{t}^{R}=1$ adjustment costs are zero when there are no price changes. The case $\pi_{t}^{R}=\pi_{t-1}^{\varsigma}$ corresponds to the case of partial indexation, with $\varsigma \in(0,1)$ representing the degree of indexation. In most of the analysis we will assume that the reference inflation rate is $\pi_{t}^{R}=1$. Therefore, through this channel increasing the inflation target introduces price distortions which tend to reduce consumption, output and welfare. ${ }^{8}$

Retail firms maximize expected profits

$$
\mathbb{E}_{0} \sum_{t=0}^{\infty} \beta^{t} \frac{\lambda_{t}}{\lambda_{0}}\left\{\left[\frac{P_{t}^{i}}{P_{t}}-\Gamma_{P t}^{i}\right] Y_{t}^{i}-\int_{0}^{Z_{t}} p_{S, t}^{j} Y_{S, t}^{j} d j\right\}
$$

subject to quadratic price adjustment costs $\Gamma_{P t}^{i}$, to the Dixit-Stiglitz demand function faced by each retailer (4), and to the retailer production function (5).

Let us denote by

$$
p_{S, t}=\left\{\int_{0}^{Z_{t}}\left(p_{S, t}^{j}\right)^{\frac{v}{v-1}} d j\right\}^{\frac{v-1}{v}}
$$

the aggregate real price of the composite of specialized goods, $\left[\int_{0}^{Z_{t}}\left(Y_{S, t}^{j}\right)^{v} d j\right]^{\frac{1}{v}}$. The first order conditions for retail firms earn a demand function for each specialized variety

$$
Y_{S, t}^{j}=\left(\frac{p_{S, t}^{j}}{p_{S, t}}\right)^{\frac{1}{v-1}} Y_{t}^{i}
$$

and a Phillips curve:

$$
\Gamma_{P t}^{\prime} \pi_{t}=\epsilon\left(p_{S, t}+\Gamma_{t}\right)-(\epsilon-1)+\beta \mathbb{E}_{t}\left[\left(\frac{\lambda_{t+1}}{\lambda_{t}}\right) \frac{Y_{t+1}}{Y_{t}} \Gamma_{P t+1}^{\prime} \pi_{t+1}\right]
$$

where we have used the fact that, in equilibrium, all retail firms set the same price and produce the same quantities. Price inflation dynamics depend on two main factors: the cost of the aggregate composite good $p_{S, t}$, which represents the marginal cost of final good retailers, and the evolution of price adjustment costs, which mainly depend on expected inflation in period $t+1$.

\footnotetext{
${ }^{8}$ In Table 9, we provide results for the case of wage indexation as, for high inflation target rates, economic agents could call for inflation compensation for not incurring large costs from price adjustments.
} 


\subsubsection{Specialized good production}

Patented goods are produced in the specialized good sector. Each patent producer $j$ produces a differentiated variety $j$ transforming one unit of the intermediate good $X_{t}^{j}$ into one unit of their patented good:

$$
Y_{S, t}^{j}=X_{t}^{j}
$$

where $X_{t}^{j}$ denotes the quantity of the intermediate homogenous goods bought by wholesaler $j$. As it is common in the literature, we allow for the possibility that the desired mark-up $\mu^{I, C}$ is lower than the optimal unconstrained mark-up $\mu^{I, U}=\frac{1}{\nu}$ due to the threat of entry by imitators (see, e.g., Anzoategui et al. (2019), and Benigno and Fornaro (2018)). In equilibrium, the optimal price is a constant markup over the price of intermediate goods, $p_{I, t}$ :

$$
p_{S, t}^{j}=\mu^{I, C} p_{I, t}
$$

and profits depend on the demand of specialized goods and are thus procyclical:

$$
\Pi_{t}^{j}=\left(\mu^{I, C}-1\right) p_{I, t} Y_{S, t}^{j}
$$

The value $V_{t}^{j}$ of owning exclusive rights to produce the specialized good $j$ using the respective patent $j$ is given by the present value of the current and future monopoly profits:

$$
V_{t}^{j}=\Pi_{t}^{j}+\left(1-\delta_{Z}\right) \mathbb{E}_{t} \beta_{t, t+1} V_{t+1}^{j}
$$

where $\delta_{Z}$ is the patent obsolescence rate and $\beta_{t, t+1}=\beta \frac{\lambda_{t+1}}{\lambda_{t}}$ is the stochastic discount factor.

\subsubsection{Intermediate production sector}

Each firm in the intermediate production sector produces according to the following technology:

$$
X_{t}=A_{t}\left(N_{t}\right)^{1-\alpha}\left(K_{t}\right)^{\alpha}
$$

where $K_{t}=z_{t} k_{t}$ denotes aggregate effective physical capital and $A_{t}$ is an exogenous technology process.

The intermediate good is sold to patent producers at the relative price $p_{I, t}$. The representative firm incurs costs in hiring and training new workers. Following, e.g., Gertler and Trigari (2009) and Gertler et al. (2008), we assume that total hiring costs are convex in the hiring rate. Specifically, let us define the hiring rate as $x_{t} \equiv \frac{q_{t} v_{t}}{N_{t-1}}$. Hiring costs are defined as

$$
h c_{t}=\frac{\kappa_{t}}{\gamma}\left(x_{t}\right)^{\gamma} N_{t-1}
$$


where $\kappa_{t}=\kappa \Psi_{t}$ and $\Psi_{t}$ is a scaling factor which ensures the existence of a balanced growth path. The assumption of convex hiring costs is based on two considerations. First, from an economic point of view, the degree of convexity $\gamma$ allows us to smooth out vacancy creation and to produce realistically persistent hiring dynamics. Moreover, as discussed, for instance in Faccini and Yashiv (2020) and Fujita and Ramey (2007), the micro evidence indicates that hiring costs are indeed convex, and that most of these costs are post-match costs related to training workers as opposed to pure vacancy posting costs. Second, from a technical point of view, the presence of convex hiring costs allows the model to meet two consistency requirements even in the presence of large shocks and long simulations: (1) that the hiring rate never turns negative, and (2) that the equilibrium wage always remains within the wage bands defined by the bargaining set.

To improve the realism of the model and the fit with the data, we also allow for nominal wage stickiness by introducing a quadratic adjustment cost function of the nominal wage $W_{t}$ :

$$
c_{t}^{W}=\frac{\phi^{w} \Psi_{t}}{2}\left(\pi_{t}^{w}-g_{t}^{R}\right)^{2}
$$

where $\pi_{t}^{w}=\frac{W_{t}}{W_{t-1}}$ denotes wage inflation, $\phi^{w} \geq 0$ determines the size of these costs and $g_{t}^{R}$ is the level of wage inflation used as reference for the adjustment costs. If $g_{t}^{R}=g^{W}$ the reference of wage adjustment costs is trend wage inflation $g^{W}$; for $g^{R}=1$ wage adjustment costs are zero when the wage is unchanged; finally, $g_{t}^{R}=\pi_{t-1}^{\varsigma}$ captures the case of partial indexation of wages to past inflation, with $\varsigma \in(0,1)$ representing the degree of indexation. Notice that, as in the case of price adjustment costs, in most of the analysis we assume that $g^{R}=1$. Therefore, a higher inflation target leads to static and dynamic wage distortion costs, which tend to decrease output, consumption and welfare.

The representative firm maximizes expected profits: ${ }^{9}$

$$
\mathbb{E}_{t}\left\{\sum_{j=0}^{\infty} \beta_{t, t+j}\left[\begin{array}{c}
p_{I, t+j}\left(A_{t+j}\left(N_{t+j}\right)^{1-\alpha}\left(K_{t+j}\right)^{\alpha}\right) \\
-\left(w_{t+j}+c_{t+j}^{W}\right) N_{t+j}-h c_{t+j}-r_{K t+j} K_{t+j}
\end{array}\right]\right\}
$$

subject to the sequence of law of motions of labour, $N_{t}=\left(1-\rho+x_{t}\right) N_{t-1}$. Maximization leads to a standard capital demand condition:

$$
r_{K t}=p_{I, t} \alpha \frac{X_{t}}{K_{t}}
$$

and to the hiring creation condition:

$\kappa_{t}\left(x_{t}\right)^{\gamma-1}=p_{I, t}(1-\alpha) \frac{X_{t}}{N_{t}}-\left(w_{t}+c_{t}^{W}\right)+\mathbb{E}_{t} \beta_{t, t+1}\left[(1-\rho) \kappa_{t+1}\left(x_{t+1}\right)^{\gamma-1}+\frac{(\gamma-1)}{\gamma} \kappa_{t+1}\left(x_{t+1}\right)^{\gamma}\right]$

\footnotetext{
${ }^{9}$ In principle, one should also include the inequality constraint requiring the hiring rate to remain positive: $x_{t} \geq 0$. Since in our simulation this constraint is never violated, we abstract from it in this paper.
} 
Finally, for later use, let us define $J_{t}$ as the the value of having a new worker after adjustment costs are sunk: ${ }^{10}$

$$
J_{t}=p_{I, t}(1-\alpha) \frac{X_{t}}{N_{t}}-\left(w_{t}+c_{t}^{W}\right)+\mathbb{E}_{t} \beta_{t, t+1}\left[\left(1-\rho+x_{t+1}\right) J_{t+1}-\frac{\kappa_{t+1}}{\gamma}\left(x_{t+1}\right)^{\gamma}\right]
$$

\subsection{Wage determination and downward wage rigidities}

Search frictions generate a surplus associated with each employment relationship. This fact has two important consequences. First, it implies that, without further assumptions, the equilibrium wage is not uniquely pinned down in our model: any wage path that generates a positive surplus for both workers and firms is privately efficient and thus consistent with equilibrium (Hall, 2005). Second, it means that once workers and firms have matched, workers enjoy some monopoly power over their wage and therefore have no longer incentives to bid the wage down. As discussed by Dupraz et al. (2019), theses two properties allow for downward wage rigidities in a search and matching model that is robust to Barro (1977)'s critique that wage stickyness should neither interfere with the efficient job formation nor lead to inefficient job destruction.

Following Acharya et al. (2021) and Dupraz et al. (2019), we incorporate downward nominal wage rigidity into the model by assuming the following wage rule:

$$
W_{t}=\max \left(\iota W_{t-1}, W_{t}^{*}\right)
$$

where $W_{t}^{*}$ is the desired nominal wage that would emerge in absence of the lower bound on nominal wages and $\iota \in(0,1)$ is a parameter limiting how much nominal wages can fall between dates $t-1$ and $t$. A value of $\iota=1$ implies that nominal wages cannot fall, while $\iota \in(0,1)$ means that nominal wages can adjust downwards to some extent. The wage rule can be rewritten in terms of real wages as follows:

$$
w_{t}=\max \left(\iota \frac{w_{t-1}}{\pi_{t}}, w_{t}^{*}\right)
$$

which shows that, even when nominal wages are not free to adjust downward, real wages can still decrease when inflation is positive. This is the main reason why positive inflation may "grease the wheels" of the labour markets (Tobin, 1972).

We assume that the desired real wage $w_{t}^{*}$ that the parties would choose in the absence of the occasionally binding constraint is a solution of Nash bargaining:

$$
\arg \max _{W_{t}^{*}}\left[\left(J_{t}\right)^{1-\eta}\left(V_{t}^{E}\right)^{\eta}\right]
$$

where $\eta$ is the bargaining power of workers and $V_{t}^{E}$ and $J_{t}$ are the values of an employment relationship for the worker and the firm (equations (2) and (8)), respectively. Bargaining over the nominal wage yields the following condition for the

\footnotetext{
${ }^{10}$ See, e.g., Gertler et al. (2008) and Sala et al. (2012) for a similar formulation and a discussion.
} 
desired real wages:

$$
w_{t}^{*}=\left(1-\varpi_{t}\right)\left\{b_{t}-\mathbb{C V}_{t}^{W}\right\}+\varpi_{t}\left\{p_{I, t}(1-\alpha) \frac{X_{t}}{N_{t}}-c_{t}^{W}+\mathbb{C V}_{t}^{F}\right\}
$$

where $\mathbb{C V}_{t}^{F}=\mathbb{E}_{t}\left[\beta_{t, t+1}\left\{\left(1-\rho+x_{t+1}\right) J_{t+1}-\frac{\kappa_{t+1}}{\gamma}\left(x_{t+1}\right)^{\gamma}\right\}\right]$ is the continuation value of the relationship for firms and $\mathbb{C V}_{t}^{W}=\mathbb{E}_{t} \beta_{t, t+1}(1-\rho)\left(1-f_{t+1}\right) V_{t+1}^{E}$ the one for workers. The variable $\varpi_{t}$ is the "effective" bargaining power of workers:

$$
\varpi_{t}=\frac{\eta}{\eta+(1-\eta)\left(1+\tau_{t, t+1}^{W}\right)}
$$

and $\tau_{t, t+1}^{W}=\frac{\partial c_{t}^{W}}{\partial W_{t}} P_{t}+\mathbb{E}_{t} \beta_{t+1}\left(\left(1-\rho+x_{t+1}\right) \frac{\partial c_{t+1}^{W}}{\partial W_{t}} P_{t}\right)$ captures the marginal costs of wage adjustments. Equation (9) shows that in the presence of wage adjustment costs, the effective bargaining power of workers becomes state-dependent. Specifically, since $\frac{\partial c_{t}^{W}}{\partial W_{t}}>0, \varpi_{t}$ increases during periods of declining wages, dampening the fluctuations of nominal wages. In this way wage adjustment costs tend to limit wage fluctuations, and reduce the probability of hitting the occasionally binding constraint on wage adjustments.

\subsection{Innovation sector}

Innovators develop new patents by conducting R\&D. They use the final good as input and sell the patent to specialized goods' producers. Assuming perfect competition, the price of a new patent equals its value to the patent producers, $V_{t}^{j}$.

The number of new patents evolves according to:

$$
Z_{t+1}=\vartheta_{t} S_{t}^{R D}+\left(1-\delta_{Z}\right) Z_{t}
$$

where $S_{t}^{R D}$ is the R\&D expenditure and $\vartheta_{t}$ represents the productivity of the R\&D sector, which is taken as given by innovating firms. Following Comin and Gertler (2006), its functional form is:

$$
\vartheta_{t}=\chi Z_{t}\left[\left(\Psi_{t}\right)^{\tau}\left(S_{t}^{R D}\right)^{(1-\tau)}\right]^{-1}
$$

where $\tau \in[0,1]$ is the elasticity of new patents with respect to $\mathrm{R} \& \mathrm{D}$ and $\Psi_{t}$ is a scaling factor that ensures balanced growth. This specification of the product innovation efficiency combines a congestion externality effect capturing decreasing returns to $\mathrm{R} \& \mathrm{D}$ investment, $\partial \vartheta / \partial S^{R D}<0$, with a knowledge spillover á la Romer (1990), where new discoveries facilitate new innovative ideas, $\partial \vartheta / \partial Z>0$.

The payoff to innovation are the discounted future profits, i.e. $\mathbb{E}_{t} \beta_{t, t+1} V_{t+1}$. Thus free entry implies that the expected sales revenues equal costs:

$$
\mathbb{E}_{t} \beta_{t, t+1} V_{t+1}\left(Z_{t+1}-\left(1-\delta_{Z}\right) Z_{t}\right)=S_{t}^{R D}
$$


which implies at the margin:

$$
\frac{1}{\vartheta_{t}}=\mathbb{E}_{t} \beta_{t, t+1} V_{t+1}
$$

This condition is crucial in the model, because it pins down the total amount of $\mathrm{R} \& \mathrm{D}$ investment and therefore the equilibrium growth rate of TFP and output in the economy.

\subsection{Monetary policy}

We assume the Central Bank sets the short term nominal interest rate by reacting to the inflation and output levels in the economy:

$$
R_{t}=\left(R_{t-1}\right)^{\varphi_{r}}\left[r\left(\frac{\pi_{t}}{\pi^{*}}\right)^{\varphi_{\pi}}\left(\frac{\hat{Y}_{t}}{\hat{Y}_{s s}}\right)^{\varphi_{y}}\right]^{1-\varphi_{r}} \varepsilon_{t}^{m}
$$

where $\hat{Y}_{t}=Y_{t} / \Psi_{t}$ is detrended output, and $\varphi_{\pi}$ and $\varphi_{y}$ are the response coefficients to inflation and detrended output. $\varphi_{r}$ captures interest rate smoothing.

\subsection{Market clearing, aggregation and TFP}

Aggregate market clearing conditions are found by aggregating across all retailers $i$ and specialized firms $j$. For instance, the market clearing condition for intermediate goods $X_{t}$ implies

$$
X_{t}=\int_{0}^{Z_{t}} X_{t}^{j} d j=Z_{t} X_{t}^{j}
$$

where we have assumed symmetry across firms. Similar conditions hold for aggregate profits of specialized firms and value of patents.

Final output, net of price and wage adjustment costs, is used for consumption, investment in physical capital, R\&D investment, and hiring costs:

$$
Y_{t}\left(1-\Gamma_{P t}\right)-c_{t}^{W} N_{t}=C_{t}+I_{t}+S_{t}^{R D}+\frac{\kappa_{t}}{\gamma}\left(x_{t}\right)^{\gamma} N_{t-1}
$$

In our model, sustained total factor productivity (TFP) growth arises endogenously through the accumulation of new patented specialized goods that facilitate the production of final retail goods. This is reflected in the production function, which after aggregation and using equilibrium conditions, is given by:

$$
Y_{t}=Z_{t}^{\left(\frac{1}{v}-1\right)} A_{t}\left(N_{t}\right)^{1-\alpha}\left(z_{t} k_{t}\right)^{\alpha}
$$


Consequently, two measures of TFP can be distinguished. Aggregate, non-adjusted, TFP is measured as:

$$
T F P_{t}=\frac{Y_{t}}{N_{t}^{1-\alpha} k_{t}^{\alpha}}=Z_{t}^{\left(\frac{1}{v}-1\right)} A_{t} z_{t}^{\alpha}
$$

while utilization-adjusted TFP is determined endogenously as

$$
T F P_{t}^{u t i l}=Z_{t}^{\left(\frac{1}{v}-1\right)} A_{t}
$$

Therefore, even when corrected for the variable utilization of capital, $T F P_{t}^{u t i l}$ varies not only with the exogenous technological component $A_{t}$, but also with the endogenous stock of intangible capital $Z_{t}$. In the following, since our empirical measure of TFP corresponds to the non-adjusted one, we will mainly study the dynamics of aggregate TFP as determined by eq. (14).

As evidenced by eq. (13), output in the long run is growing endogenously with the stock of intangible capital. To ensure balanced growth, we assume that the scaling factor is

$$
\Psi_{t}=Z_{t}^{\Upsilon}
$$

where $\Upsilon=\frac{\left(\frac{1}{v}-1\right)}{(1-\alpha)}$.

\section{Calibration and solution method}

In this section, we discuss the calibration strategy, the solution method and the model fit relative to the moments of the euro area data for the variables of interest.

\subsection{Calibration}

The model is calibrated at the quarterly frequency. The values of the parameters are chosen to capture the main structural features of the Euro Area and are close to the standard values used in the literature. The empirical targets correspond to the Euro Area in the period 1999q1 to 2019q4.

Long run inflation target and average growth. In the baseline calibration, we assume that the central bank targets an annualized inflation of 1.8 percent, consistent with the official inflation objective of the European Central Bank of "below, but close to 2 percent". The scale parameter $\chi$ is chosen to match the average annual TFP growth rate, $g_{T F P}=0.84$ percent, since the creation of the Euro. This correspond to an average output growth rate of $g=1.2$ percent which is only slightly larger than the value of $g=1.11$ in the data.

Preferences. The discount factor $\beta$ is set to 0.997, as in Amano and Gnocchi (2020). The elasticity of substitution of retail goods is $\epsilon=6$, corresponding to a steady state markup in the retail sector of about 20 percent. 
Wage and price adjustment costs. To increase realism and the fit with the data, the model includes both moderate price and wage adjustment costs, and occasionally binding constraints that limit negative wage inflation. We set the degree of price rigidities, $\phi^{p}$, to a value that corresponds to a Calvo parameter of 0.58 which represents a mean price duration of about 7 months. This value is very close to the values used in Coibion et al. (2012) and Amano and Gnocchi (2020), and only slightly below the value of 0.63 assumed by Fahr and Smets (2010). The wage adjustment cost parameter $\phi^{w}$ is set to match the observed relative volatility of employment. We get $\phi^{w}=10.5 .^{11}$ Regarding the level of the occasionally binding constraint on nominal wages, in the baseline calibration we set $\iota=1$, as in Acharya et al. (2021) and Dupraz et al. (2019). In robustness exercises, we also consider the case of a negative effective lower bound on wage inflation.

Labour markets. The steady state unemployment rate is set to 9 percent and the quarterly job separation rate to 0.06 . The implied value for the job finding rate is $f=0.378$. These values are in line with the empirical analysis by Elsby et al. (2009) for a number of continental European countries. The quarterly job filling rate is set to $q=0.6$. The workers' bargaining power $\eta$ and the elasticity of job matches with respect to vacancies, $\zeta$, are both set to 0.5 , as it is standard in the literature, see, e.g., Petrongolo and Pissarides (2001) and Blanchard and Galí (2010). As in Cacciatore and Fiori (2016) we set the real unemployment benefits, $b$, by targeting a replacement rate of $b / w=0.62$ in steady state, close to the average replacement rate in the Euro Area. We assume quadratic hiring costs $(\gamma=2)$, as in Gertler and Trigari (2009). The hiring costs parameter $\kappa$ and the matching efficiency parameter $\bar{m}$ are determined through steady state relationships. The implied total hiring costs are 1.31 percent of total output, in line with Faccini and Yashiv (2020), who calibrate them on the basis of German and Swiss micro-data.

R\&D sector. Following Guerron-Quintana and Jinnai (2019) we set the patent obsolescence rate to $\delta_{Z}=0.03$. The elasticity of new technologies to $\mathrm{R} \& \mathrm{D}$ is calibrated to 0.85, in between the values chosen by Kung and Schmid (2015) and Guerron-Quintana and Jinnai (2019).

Production. We set the elasticity of intermediate production to capital, $\alpha$, to 0.3. Following Anzoategui et al. (2019), we set $v=0.74$ to produce an elasticity of substitution of 3.85 between specialized goods, while the markup on specialized goods is set to $\mu^{I, C}=1.18$, in the middle of the range of the estimates in the literature. The elasticity of capital depreciation to changes in utilization is parametrized such that the steady state value of the utilization rate $z$ equals unity. We get $\phi_{k}=1.30$, a value close to the ones used, e.g., in Greenwood et al. (1988) and Neiss and Pappa (2005). The quarterly capital depreciation rate is set to $\delta=0.02$, corresponding to an annual depreciation rate of 8 percent. The investment adjustment cost is set to $\Theta_{I}=0.17$, in order to broadly match the relative standard deviation of investment to GDP. The steady state value of technology, $A$, is chosen so that output in the

\footnotetext{
${ }^{11} \mathrm{We}$ target the relative employment volatility instead of the wage volatility because of the well known difficulties in measuring aggregate wages in the data. See, e.g., Justiniano et al. (2013).
} 
steady state of the detrended system is normalized to one.

Monetary policy. We calibrate the parameter governing the sensitivity of interest rate to inflation to $\varphi_{\pi}=1.5$, the sensitivity to output to $\varphi_{y}=0.1$ and the degree of interest rate smoothing to $\varphi_{r}=0.85$.

Shock processes. In the baseline calibration, we consider three sources of variation: monetary policy shocks, exogenous TFP shocks and risk premium shocks. The persistence and volatility of the risk premium shocks are calibrated to $\rho_{\varrho}=0.92$ and $\sigma_{\varrho}=0.2$ percent. These values are close to the calibrated parameters used in Coibion et al. (2012), to the estimated values in Anzoategui et al. (2019) and Andrade et al. (2019) for the US and in Andrade et al. (2021) for the Euro Area. The persistence parameter of the exogenous technology shocks is set to $\rho_{Z}=0.95$, as standard in the literature. The volatility of the exogenous technology shocks is set to $\sigma_{z}=0.45$ percent in order to match the average volatility of GDP per capita. The standard deviation of monetary policy shocks is set to 0.1 percent, consistent with the estimates by Christoffel et al. (2009).

Table 1: Calibration baseline model

\begin{tabular}{|c|c|c|}
\hline Parameters & Values & Source \\
\hline Inflation target & 1.8 & ECB objective \\
\hline SS growth rate & 1.2 & Avg TFP growth rate $=0.84 \%$ \\
\hline Price rigidity $\phi^{p}$ & 16.37 & Calvo param. 0.58 \\
\hline Wage rigidity $\phi^{w}$ & 10.5 & Match $\operatorname{std}\left(N_{t} / Y_{t}\right)$ \\
\hline Discount factor $\beta$ & 0.997 & Amano\&Gnocchi (2020) \\
\hline Elast. new patents to $\mathrm{R} \& \mathrm{D} \tau$ & 0.85 & Kung\&Schmidt (2015) \\
\hline Patent obsolescense rate $\delta_{Z}$ & 0.03 & Guerron-Quintana\&Jinnai (2019) \\
\hline \multicolumn{3}{|l|}{ Shocks } \\
\hline Std.dev. interest rate $\sigma_{m}$ & $0.1 \%$ & Christoffel et al.(2008) \\
\hline Autocorr. exog. tech. $\rho_{z}$ & 0.95 & Sahuc\&Smets(2008) \\
\hline Std.dev. exog. tech. $\sigma_{z}$ & $0.45 \%$ & Match $\operatorname{std}(y)$ \\
\hline Autocorr. of risk premiv & 0.92 & Anzoategui el al.(2019); Andrade et al. (2021) \\
\hline Std. dev. risk premium $\sigma_{\varrho}$ & $0.2 \%$ & Anzoategui el al.(2019); Andrade et al. (2021) \\
\hline
\end{tabular}

The table shows the calibration of selected parameters for the baseline model.

Benchmark models. In our analysis, we compare our baseline model to two, nested, benchmark models: a model without downward wage rigidities (Endo. growth - no $D W R$ ) and a model in which we additionally shut-down the endogenous growth channel (Exo. growth - no DWR). This allows us to study the individual contributions from DWR and endogenous growth to our findings and to which extent their interaction matters. All benchmark models include search and matching unemployment. The model without DWR is obtained by simply abstracting from the occasionally binding constraint on wage adjustment. The model with exogenous growth is a version of our model with constant R\&D investment intensity. This is 
equivalent to specifying an exogenous trend growth component in productivity. ${ }^{12}$ To facilitate comparison, the calibration of the benchmark models is identical to the one of the baseline model with endogenous growth and DWR.

\subsection{Solution method and model fit}

The model is solved at the second order by using the DynareOBC toolkit for solving models with occasionally binding constraints by Holden (see e.g. Holden (2016) and Holden et al. (2020)). ${ }^{13}$ The algorithm allows computing accurate solutions accounting for precautionary behavior associated with the bound. However, producing average impulse responses at this high level of accuracy is computationally difficult. Therefore, following Holden et al. (2020), for consistency we solve the model at the second order but treating the bounds in a perfect-foresight manner throughout. This choice also allows a closer comparison with previous research (e.g. Coibion et al. (2012) and Amano and Gnocchi (2020)), which adopt an identical perfect-foresight assumption but solve the model at the first order. It can be shown that the main results of the paper are not affected by this choice.

Table 2: Long-run means

\begin{tabular}{lccccc}
\hline & UR & $\Delta y$ & $\Delta T F P$ & $\pi$ & $\pi^{w}$ \\
\hline Steady-state & 9.00 & 1.20 & 0.84 & 1.80 & 3.00 \\
Data & 9.41 & 1.11 & 0.83 & 1.68 & 2.07 \\
DWR model - End. growth & 9.55 & 1.14 & 0.80 & 2.13 & 3.27 \\
\hline
\end{tabular}

The table shows the long run mean (percent, annualized) of selected variables in the steady state of the model, in the euro area data and in the baseline model.

Tables 2 and 3 compare the first and second moments of the data with those predicted by our baseline model. ${ }^{14}$ The moments of the model are obtained by simulating 101000 periods, discarding the first 1000. Long run means of output, TFP growth and inflation are annualised and expressed in percentage terms. Second moments are obtained by filtering the actual and simulated data with the $\operatorname{HP}(1600)$ filter.

Overall, the model does a remarkably good job in matching most of the moments of the data. In particular, the model reproduces very closely the long-run means of unemployment, output and TFP growth, although the long run mean of price inflation and, especially, wage inflation is slightly larger than in the data (Table 2). This can be explained by noticing that (1) output growth has been lower in recent years than what could be expected given average TFP growth, and (2) average inflation

\footnotetext{
${ }^{12}$ See Kung and Schmid (2015) for a similar strategy.

${ }^{13}$ DynareOBC is available at https://github.com/tholden/dynareOBC.

${ }^{14}$ Table 11 and 12 provide long-run means and second moments also for the other two benchmark models.
} 
in the euro area has been lower than the inflation target of the European Central Bank. The model also replicates well absolute and relative standard deviations of the data, and the co-movements of the main variables with output (Table 3).

Table 3: Business cycle moments

\begin{tabular}{|c|c|c|c|c|}
\hline \multirow[b]{2}{*}{ Variable $(X)$} & \multicolumn{2}{|c|}{$\sigma(x) / \sigma(y)$} & \multicolumn{2}{|c|}{$\rho(x, y)$} \\
\hline & Data & Model & Data & Model \\
\hline Unemployment & 4.55 & 4.67 & -0.88 & -0.69 \\
\hline Employment & 0.52 & 0.52 & 0.83 & 0.68 \\
\hline Investment & 2.34 & 2.34 & 0.86 & 0.88 \\
\hline Consumption & 0.55 & 0.47 & 0.84 & 0.90 \\
\hline $\mathrm{TFP}$ & 0.79 & 0.81 & 0.97 & 0.95 \\
\hline Nominal wages & 0.16 & 0.46 & 0.31 & 0.63 \\
\hline Prices & 0.50 & 0.80 & 0.20 & 0.53 \\
\hline Real wages & 0.46 & 0.73 & -0.13 & -0.08 \\
\hline$\sigma(y)$ & 1.20 & 1.20 & & \\
\hline
\end{tabular}

The table shows the HP(1600)-filtered second moments of selected variables in the euro area data and in the baseline model.

\section{Endogenous growth dynamics with occasionally binding wage constraints}

The first question we seek to address is how accounting for endogenous growth and downward rate rigidities (DWR) affects some of the key considerations relevant for monetary policy making. This includes the effect on the dynamics of the economy and the policy trade-off between output growth and inflation. For this purpose we analyse, first, how these features affect the impulse responses to demand shocks; second, how this translates into long-term output and unemployment performance when combined with other shocks; and third, how the long-run Phillips curve, which describes the policy trade-off faced by the monetary policy authority, is altered.

\subsection{Permanent asymmetric response to shocks}

In this section we describe in detail the response of the economy to risk premium shocks. We focus on the risk premium shock, as the relevant demand shock in the recent past, which triggers a simultaneous decline in output and prices and amplifies the relevance of DWR. Using the response to demand shocks, we describe how the economy's response to temporary symmetric shocks can have permanent 
asymmetric effects in our model. ${ }^{15}$ This finding implies that medium-term dynamics are a function of the history of shocks in models accounting for endogenous growth and downward wage rigidities.

Figure 2: Impulse Response to Large Negative Risk Premium Shock
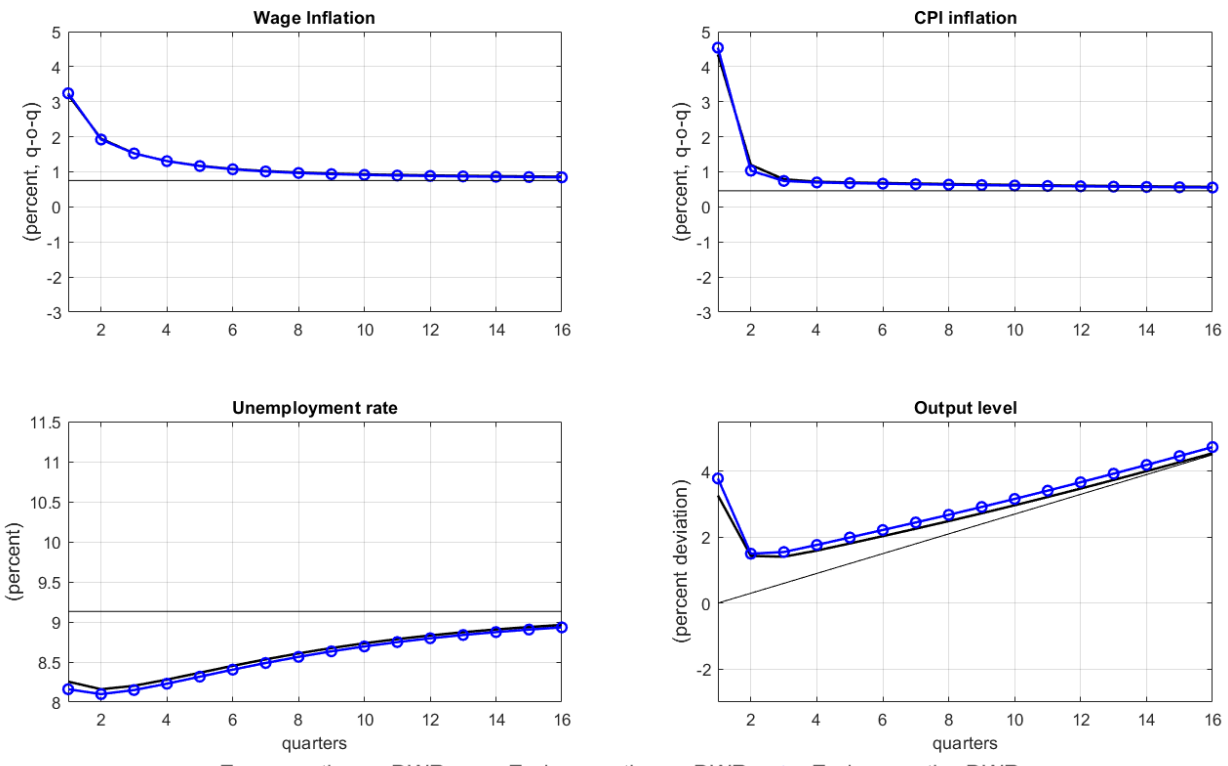

—Exo. growth - no DWR ------Endo. growth - no DWR -0-Endo. growth - DWR

Figures 2 and 3 show the responses of wages, inflation, unemployment and the output level to large negative and positive risk premium shocks, respectively. The size of the shock corresponds to a change in the risk premium of about three percent annualized, broadly similar to episodes of significant financial distress. ${ }^{16}$ A quick glance at Figure 2 reveals that the differences between the exogenous growth and endogenous growth models are rather limited, for a negative risk premium shock. The reduction of risk premiums encourages households and firms to increase consumption and investment, and leads to an increase in hiring and production. Price and wage inflation, however, increase relatively fast, slowing down job-creation and the ensuing unemployment reduction. Comparing the model with and without endogenous growth, one can notice that unemployment drops and output increases slightly more on impact in the endogenous growth model, reflecting the higher expected future profits, which trigger a boost to innovation in the short-term (see equation 10). The implied increase in the stock of $R \& D$ allows for a higher level of productivity, shifting the output level of the endogenous growth model up relative to its exogenous growth counter-part. Downward wage rigidities are irrelevant for the negative shock, making the line indistinguishable from the simple endogenous growth model.

\footnotetext{
${ }^{15}$ The impulse response functions focus on the first four years and we look at the long-run effects in the next subsection.

${ }^{16} \mathrm{~A}$ large shock is required to reach the occasionally binding constraint (OBC) for wages, when starting from the steady-state growth path. This does not imply that the OBC is reached only when such large shocks occur. Conditional on the economy being already close to the OBC (e.g., following a series of smaller shocks), a relatively moderate shock would trigger similar dynamics.
} 


\section{Figure 3: Impulse Response to Large Positive Risk Premium Shock}
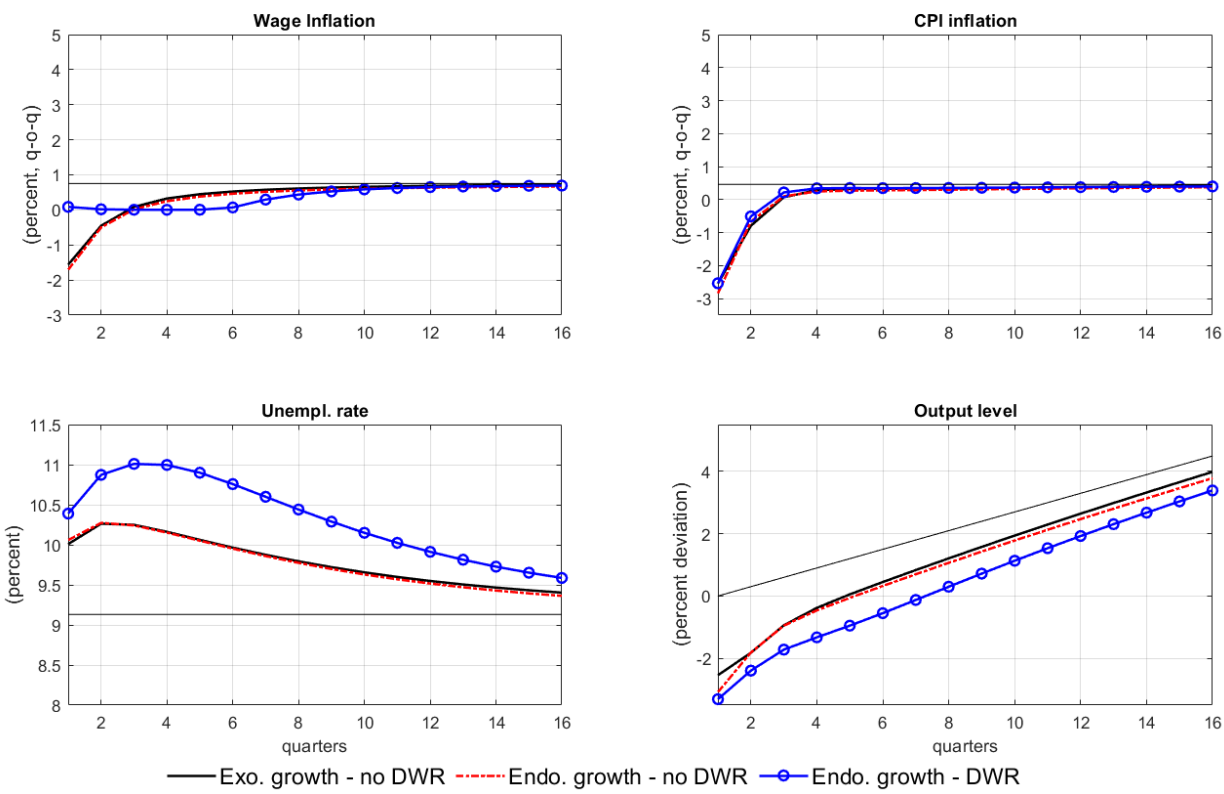

The results are very different following an increase in risk premiums (Figure 3). It is again the case that the endogenous and exogenous growth model without downward wage rigidities differ only by the stronger effect on impact and the slight output level shift for the endogenous growth model over the medium-term. However, once downward wage rigidities are considered, the output contraction becomes more severe on impact and the level of output does not recover to the same level as in the models without downward wage rigidities. This happens because price inflation goes down, but wage inflation can not go below zero because of the occasionally binding wage constraint. As a consequence, real wages actually increase during the recession, amplifying the negative impact of the shock on the labour market and the whole economy. The reaction of the unemployment rate in the DWR model is twice as large and much more persistent. With discounted future profits depressed by the associated lower demand, R\&D investment declines and leads to a persistent drop in intangible capital and productivity. The output level drop is much stronger and more persistent, as it converges to a permanently lower balanced growth path. ${ }^{17}$

Comparing the impulse responses following a positive (Figure 2) and negative (Figure 3) demand shock one can grasp the key mechanism behind our results. Through the combinations of DWR and endogenous productivity, our model is able to (1) reproduce strong asymmetric responses of unemployment, wage inflation, and output; and (2) generate output and TFP hysteresis. Importantly, the combination of these two results implies that business cycle shocks can, little by little, shift down

\footnotetext{
${ }^{17} \mathrm{~A}$ model with downward wage rigidities and exogenous growth would be close to our model for the response of wage and unemployment. However, the response of output would be closer to the benchmark models depicted here, due to the missing feedback from lower demand and profits to the level of R\&D investment and productivity.
} 
the level of output and TFP. Therefore, the average observed growth rate of the model will be lower than the one implied by the non-stochastic steady state of the model.

Because the above mechanism requires that nominal wages hit the lower wage bound, it is likely to be quantitatively important either when the economy is hit by a large shock, or when a series of negative shocks hit an economy that is already close to the wage bound. This observation is consistent with an economy that generally experiences relative calm, with rather symmetric business cycles, intermittently disrupted by shocks that generate long-lasting asymmetric responses.

\subsection{Long-run dynamics and output losses}

The preceding analysis highlighted how the introduction of endogenous growth and downward wage rigidities generates asymmetric and persistent responses to large demand shocks. We now discuss what this implies quantitatively for the economy's long-run dynamics. For this purpose, we simulate long samples of our quarterly models under the combination of calibrated monetary, technology and risk premium shocks described in Section 3. ${ }^{18}$

As an illustrative example, Figure 4 depicts the paths for wage and price inflation, the unemployment rate and the output level by extracting 100 years of simulated annual data from the long simulations above for our baseline model with DWR and endogenous growth and the two benchmark models. The starting conditions as well as the sequence of shocks are identical in all cases.

Three main results stand out from these simulations. First, the model is able to reproduce the plucking property of data documented, e.g., by Dupraz et al. (2019), whereby the unemployment rate tends to increase more and faster in recessions, than it decreases during expansions. Second, departures of the trajectories of the unemployment rate across different models happen exactly in the periods when the occasionally binding constraint on wage adjustment is binding, confirming that the presence of DWR creates the plucking property of the model. Finally, from the dynamics of the output level one can notice that the three models generate almost identical trajectories for the first thirty years of simulated data, until a series of negative shocks lead the economy to hit the wage constraint and drift the model economies apart.

The lower output level in the endogenous growth model compared to the exogenous growth model (both without DWR) derives from the former's higher output volatility (reflected also by the stronger response of output and unemployment to the risk shock in Figures 2 and 3) which in turn depresses average investment activity and thereby reduces the long-run level of TFP. The asymmetric response to positive ver-

\footnotetext{
${ }^{18}$ As described above, long-run simulations refer to 100000 periods and second moments are computed after filtering the simulated data with the $\operatorname{HP}(1600)$ filter.
} 
Figure 4: Wages, price, unemployment and output dynamics, 100 years
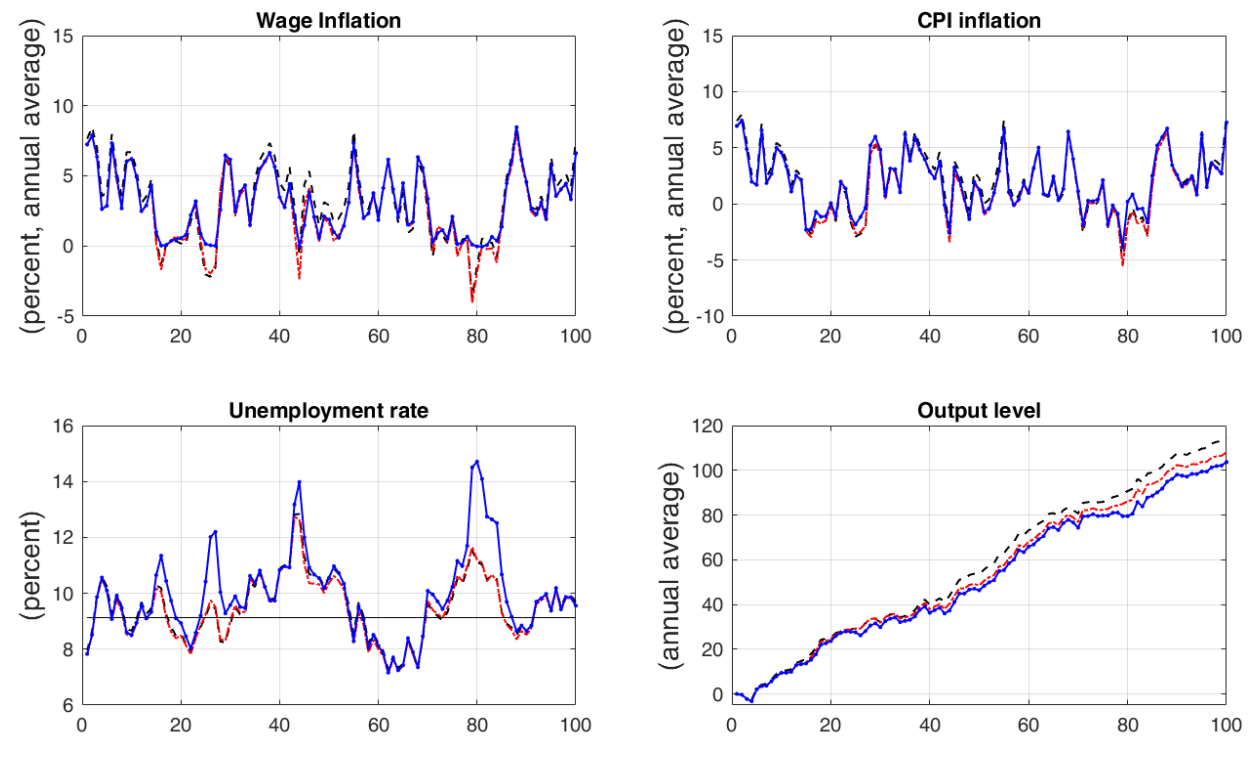

- - - Exo. growth - no DWR ------.Endo. growth - no DWR —-Endo. growth - DWR

sus negative shocks in the endogenous growth model with downward wage rigidities is the source for the additional reduction in the output level. The latter effect is on average more important in accounting for the output differential as shown in Table 4 , which shows average values across our entire sample of simulated data. ${ }^{19}$ The two models without downward wage rigidities have almost identical long-run unemployment rates, but endogenous growth implies a lower average output growth by around 0.02 percentage points per year. While small in a single year, this adds to a loss of more than 2 percent over 100 years. When nominal wages are prevented from declining, this loss increases significantly to almost 6 percentage points. The higher loss is a consequence of hitting the wage constraint on average with a probability of 11 percent. Conditional on having reached the lower bound the odds of remaining there increase, as the lack of real wage adjustments delays the recovery. This implies a probability of being at the lower bound of 22 percent in our baseline calibration ${ }^{20}$.

\subsection{Trade-offs for the long-run Phillips curve}

The previous sections described how the presence of DWR and endogenous growth generate permanent long-term output losses through asymmetric (negative) effects from temporary symmetric shocks. Next we discuss what this implies for the longrun slope of the Philips curve and as a result for the monetary-policy invariance

\footnotetext{
${ }^{19}$ Additional long-run equilibrium outcomes computed as the ergodic means of the simulated data are shown in Table 11, which also includes a comparison across models that highlight the relative contribution from the endogenous model with downward wage rigidities.

${ }^{20}$ As shown in Section 5 and Appendix A our findings and conclusions are robust to lower probabilities of hitting the occasionally binding constraint.
} 
Table 4: Long-run means: baseline and benchmark models

\begin{tabular}{|c|c|c|c|c|c|}
\hline Model variation & $\mathrm{UR}$ & $\Delta y$ & $\operatorname{Pr}\left(w_{t} \leq \bar{w} \mid w_{t-1}>\bar{w}\right)$ & $\operatorname{Pr}(w \leq \bar{w})$ & $y_{t=100}^{i}-y_{t=100}^{E x}$ \\
\hline \multicolumn{6}{|l|}{ Benchmark } \\
\hline Exogenous growth & 9.19 & 1.20 & 0.0 & 0.0 & 0.0 \\
\hline Endogenous growth & 9.15 & 1.18 & 0.0 & 0.0 & -2.27 \\
\hline \multicolumn{6}{|l|}{ Baseline } \\
\hline Endogenous growth \& DWR & 9.55 & 1.14 & 0.11 & 0.22 & -5.79 \\
\hline
\end{tabular}

The table shows the long-run means for baseline and benchmark models.

hypothesis (Blanchard, 2018; Hall and Sargent, 2018). To do so, we simulate the model for values of the inflation target that go from 0.5 to 6 percent and study how the ergodic means of output growth and the unemployment rate vary for different values of the target. For each value of the inflation target we allow the steady state of the model to adjust endogenously, thus accounting also for the long run distortions arising from price and wage rigidities. In our model, an increase of the inflation target produces two opposite effects on the economy: on the one side, it reduces the probability of hitting the occasionally binding wage constraint, thus potentially improving the long run equilibrium of the model. On the other side, a higher inflation target increases the distortions arising from quadratic price and wage adjustment costs, which in turn tend to reduce output, consumption and employment.

Figure 5 depicts the long-run Phillips curve relationship between inflation and unemployment and a related, but less often considered, relationship between inflation and output growth for our model and the two benchmark models. Focusing first on the traditional long-run Phillips curve, we confirm the results by Benigno and Ricci (2011) and Dupraz et al. (2019) of a negative relationship between inflation and the unemployment rate at low levels of inflation. At low levels of inflation the occasionally binding constraint binds more frequently, which increasingly dominates the efficiency loss from price adjustment costs, leading to higher unemployment. This is in contrast to an almost vertical, but monotonically upward sloping Phillips curve in both benchmark models without DWR, where only price distortions matter.

Our model adds a new dimension by extending the effect to the relationship between inflation and output growth. Traditional models imply long run neutrality - i.e., growth is invariant to the inflation rate. This is shown by the vertical line in the right panel of Figure 5 for the exogenous growth model. Our model suggests a deviation from this concept even in the long run. Endogenous growth, in the absence of DWR, implies a downward sloping relationship between the inflation target and output growth: a higher inflation target increases price and wage distortions, which in turn reduce $R \& D$ investment and long run growth. Adding DWR introduces the trade-off between price and wage adjustment costs and the costs related to DWR and leads to a highly non-linear long run Phillips curve: the Phillips curve is positively sloped for low levels of inflation but turns downward sloping for inflation 


\section{Figure 5: Unemployment and output growth Phillips curves}
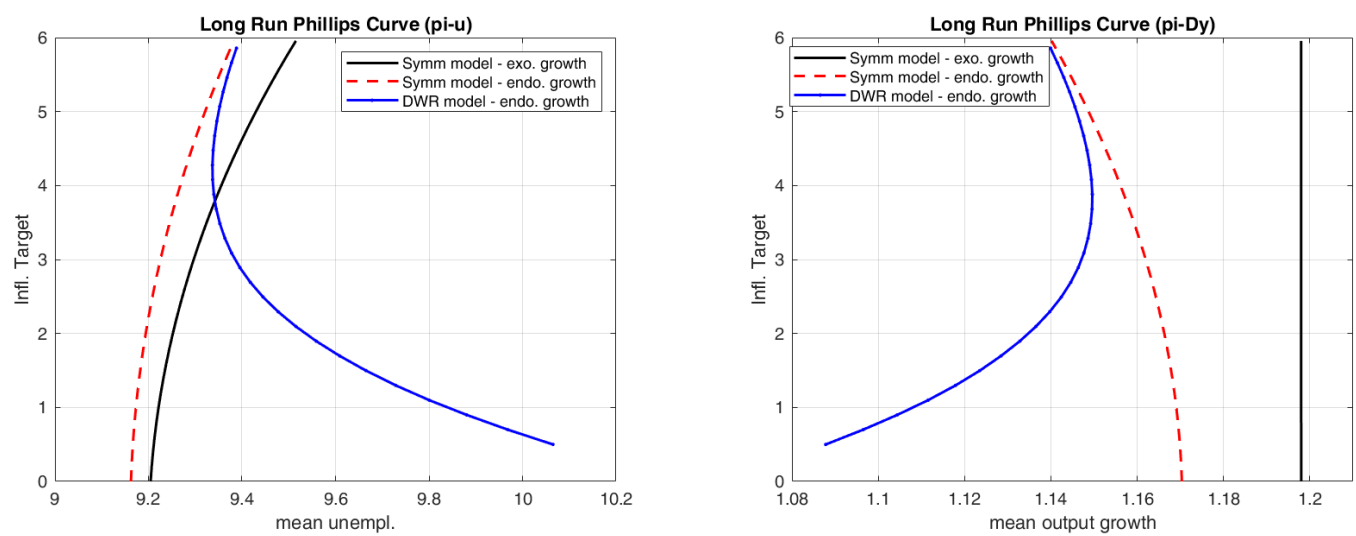

rates above $4 \%$. This happens because the trade-off in the traditional Phillips curve between unemployment and inflation is translated via changes in investment in $R \& D$ into corresponding changes in output growth. This effect is small on average, but becomes important if coumpounded for many years or in specific episodes when the wage constraint is binding.

The extent to which the long-run inflation-output trade-off matters crucially depends on two factors in our model: (i) the economy's long-run growth rate, and (ii) the size and persistence of demand (risk premium) shocks. The average growth rate and the inflation target are important because, together, they determine the distance of steady state wage inflation from the wage bound. The size and persistence of risk premium shocks, instead, determine the probability of having a sequence of shocks that are large enough to lead the economy to the occasionally binding wage constraint.

Figure 6 shows visually the importance of these factors on the slope and position of the long run Phillips curve of our stylized economy. A higher long-term growth rate is synonymous of higher steady-state productivity growth in our model. Since wage growth in the steady-state is proportional to labour productivity growth, this implies that the distance between the wage floor and the the equilibrium wage growth is larger under higher steady-state TFP growth. Consequently, for identical shock distributions, the probability of being at the wage floor is reduced and DWR become increasingly irrelevant. The curve reflecting the trade-off between the unemployment and the inflation rate rotates to the left for lower levels of inflation. Through the endogenous growth channel, this translates into a movement of the curve describing the trade-off between inflation and output growth to the right, making it steeper. On the contrary, a higher volatility of risk premium shocks shifts the Phillips curve between inflation and growth to the left, implying that for a given inflation rate the output loss is higher for a larger variance in risk premium shocks. The reason for the shift is that the asymmetric effects become larger for a given frequency of hitting the lower wage bound. ${ }^{21}$

\footnotetext{
${ }^{21}$ Because endogenous growth implies a more persistent response, the duration of episodes at
} 
Figure 6: Phillips curves under different calibrations

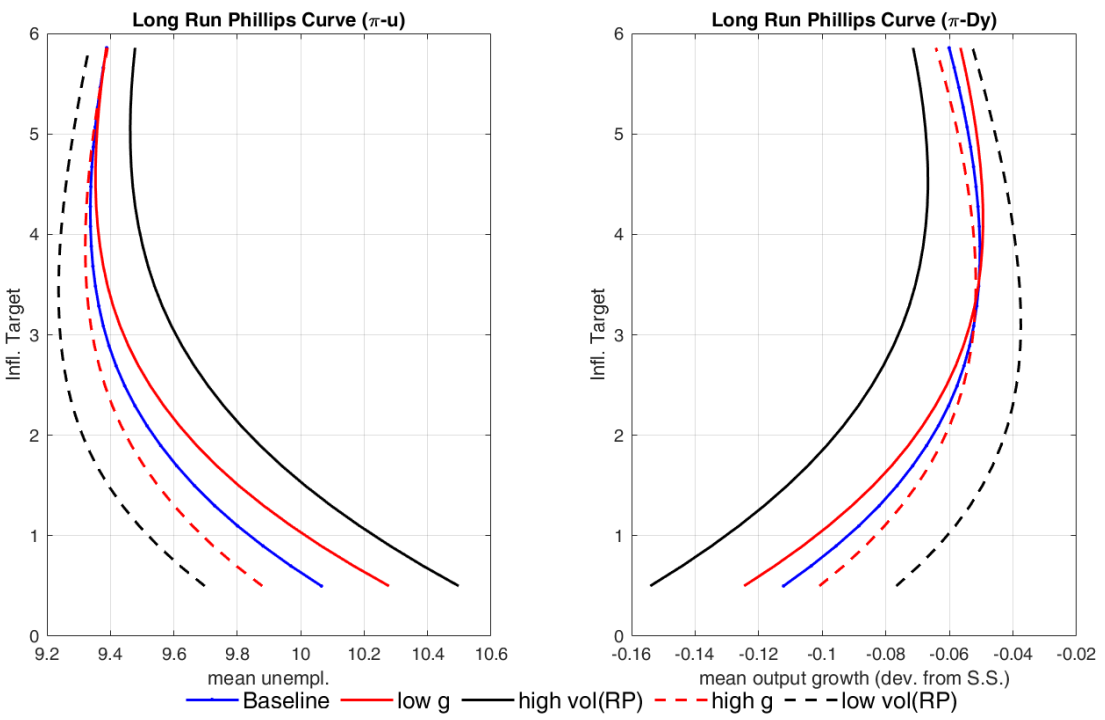

These results have potential implications for the monetary policy framework in view of the secular trends in productivity growth and the low inflation environment, which have become more evident and entrenched following the Global Financial Crisis. At the start of the Economic and Monetary Union, long-term output growth and average price inflation were about two percent each, while the variance in the size of demand shocks may have arguably been lower. ${ }^{22}$ More recently, the longterm averages for output growth and inflation have almost halved. ${ }^{23}$ In such an environment, the non-vertical part of the long-run Phillips curve is more likely to be the norm rather than the exception and the slope may have flattened.

\section{The optimal inflation rate}

Equipped with the results from the preceding section on how endogenous growth and DWR alter the trade-offs faced by monetary policy, we derive the implications for the optimal inflation target and quantify the welfare costs of deviating from it. For this purpose, we first describe the welfare metric that allows us to handle the properties of our model and then proceed with simulations to compute the welfare losses over a fine grid of inflation targets from zero to six percent.

the bound is also increased, contributing additionally to a slight shift in the curve, as for a lower steady state growth.

${ }^{22}$ This was the economic environment prevailing during the first monetary policy strategy review in 2003, which led to the numerical definition of the ECB price stability of close but below $2 \%$.

${ }^{23}$ The 10-year average of output growth and inflation fell from about $2 \frac{1}{4}$ and 1.9 percent before the global financial crisis to 1.0 and 1.3 percent in the 10 years before the COVID shock, respectively. 


\subsection{Welfare metric}

To measure welfare in a non-stationary environment, we adopt a strategy inspired by Lucas (1987) and Barlevy (2004). We define the growth rate of consumption as $g_{C, s} \equiv \frac{C_{s}}{C_{s-1}}$ and use $C_{t}=\left(\prod_{s=1}^{t} g_{C, s}\right) C_{0}$ to rewrite lifetime utility, $\mathcal{V}_{0}=$ $\mathbb{E}_{0} \sum_{t=0}^{\infty} \beta^{t} \log \left(C_{t}\right)$, as

$$
\mathcal{V}_{0}=\frac{1}{1-\beta}\left[\log \left(C_{0}\right)+\mathbb{E}_{0}\left(\sum_{t=1}^{\infty} \beta^{t} \log \left(g_{C, t}\right)\right)\right]
$$

Therefore, unconditional welfare can be estimated as

$$
\mathbb{E} \mathcal{V}_{0}=\frac{1}{1-\beta}\left[\mathbb{E} \log \left(C_{0}\right)+\frac{\beta}{(1-\beta)} \mathbb{E} \log \left(g_{C, t}\right)\right]
$$

We can thus approximate welfare by computing the ergodic means of log consumption and $\log$ consumption growth from long simulations of the model. Notice that, since the discount factor $\beta$ is close to 1 , equation (15) implies that small differences in average growth rates can have substantial welfare consequences.

In practice, we analyze welfare gains and losses of different versions of the model by computing consumption-equivalent differences from the welfare-maximizing steady state. Since changes in the inflation target affect both the non-stochastic steady state and the dynamics of the economy, we compute welfare losses in deviation from the maximum welfare level in steady state; that is the welfare of the steady state corresponding to a zero inflation target. This ensures a unique reference point for welfare comparison. Formally, the fraction of consumption that would need to be sacrificed in each period in the reference case to yield the same welfare as in the alternative case, $\gamma_{C E}$, is found as

$$
\gamma_{C E}=\exp \left((1-\beta)\left(\mathbb{E} \mathcal{V}_{M}-\mathbb{E} \mathcal{V}_{A}\right)\right)-1
$$

where $\mathbb{E} \mathcal{V}_{M}$ is welfare in the welfare-maximizing steady state and $\mathbb{E} \mathcal{V}_{A}$ denotes welfare in the alternative case under consideration.

\subsection{The cost of deviating from optimal inflation}

Figure 7 describes what the computation of the welfare metric yields for our models over a grid of inflation targets from zero to six percent. The figure depicts along the $\mathrm{x}$-axis the inflation target and on the $\mathrm{y}$-axis the implied consumption equivalent welfare losses based on long simulations of the three models under the calibration and shocks distributions described in Section 3.

Four main results emerge from this analysis: First, we find that for the benchmark models without DWR the welfare cost is minimized at an inflation target of zero. This is an immediate consequence of the price and wage adjustment costs which are 


\section{Figure 7: Welfare under different inflation targets and models}

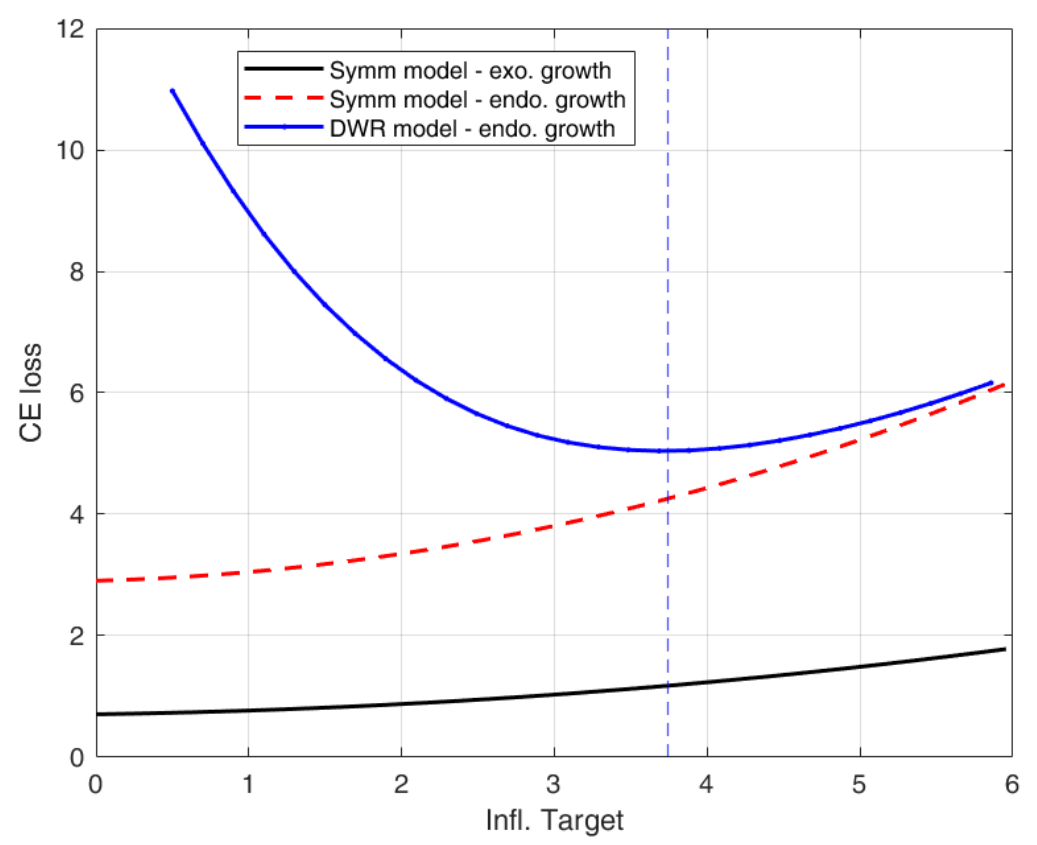

increasing in the level of inflation. Absent DWR, a higher inflation target amplifies price and wage distortions, which are the main distortions directly related to the inflation target that generate inefficient misallocation.

Second, the inclusion of endogenous growth amplifies the losses associated with price and wage adjustment inefficiencies. Even absent DWR, endogenous growth increases consumption equivalent welfare losses by more than $2 \%$. This happens because with endogenous productivity, higher price and wage distortions translate into lower average investment in R\&D and TFP growth, and transform temporary shocks into more persistent deviations from the optimal allocation.

Third, the inclusion of downward wage rigidities generates a trade-off for the optimal inflation target, consistent with the trade-off shown in section 4.3 for the long-run Phillips curve. The consumption-equivalent welfare loss is U-shaped with respect to the inflation target: for low levels of the inflation target, the costs related to DWR prevail and therefore increasing the target reduces the welfare losses; for an inflation target above its optimal level the distortions related to price rigidities are larger and tend to dominate over the costs of DWR. Importantly, amidst the deviation from neutrality implied by our model, and the asymmetric nature of the occasionally binding wage constraint, the optimal inflation rate which maximizes welfare is more than 3 percent, well above what is implied by standard New Keynesian models.

Fourth, the combined presence of DWR and endogenous growth generates significant welfare gains from adopting the optimal inflation target. In models without endogenous productivity, deviations from the optimal inflation target are associated with relatively modest consumption equivalent welfare losses. This can be seen for 
the exogenous growth model in Figure 7, which shows that increasing the inflation target from $1 \%$ to $4 \%$ increases welfare losses by less than 0.5 percentage points. In the model with both DWR and endogenous growth, the loss difference increases to more than 5 percentage points over the same target range. This is because deviations from the optimal target carry significant welfare losses as they are associated with changes in average output growth, absent in (exogenous growth) NK models.

To investigate further which factors drive these results, Table 5 shows how the optimal inflation target changes once we close sequentially the three main frictions of the model: endogenous growth, search frictions and DWR. The endogenous growth channel has a strong effect on the welfare costs of business cycles, which are reduced by a factor of 4 (comparing model (1) in the table with the baseline), but has a more limited effect on the optimal inflation target, which is reduced by 0.6 percent, from 3.76 to 3.16. Reducing additionally the importance of search frictions, by limiting the total hiring costs as a fraction of output to one fourth the baseline cost, the optimal inflation target is further reduced to 1.1 percent. Hence, search frictions and associated unemployment have a crucial role in amplifying the costs of DWR and requiring a higher inflation target. This happens because, search frictions strongly increase the duration and severity of recessions, and higher recruitment costs reduce the amount of output that can be dedicated to consumption (see equation 12).

Table 5: Decomposing the drivers of the optimal inflation target

\begin{tabular}{lcccc}
\hline Model variation & Optimal & \multicolumn{2}{c}{ Welfare Loss at } & $\Delta$ Loss \\
\cline { 3 - 4 } & $\pi^{*}$ & $\pi=\pi^{*}$ & $\pi=1.8$ & $\left(\pi^{*}-1.8\right)$ \\
\hline Baseline & 3.76 & 4.34 & 6.05 & -1.72 \\
\hline (1) Baseline without endogenous growth & 3.16 & 1.19 & 1.35 & -0.15 \\
(2) Lower search frictions + (1) & 1.10 & 4.34 & 4.42 & -0.08 \\
(3) No DWR + (2) & 0.00 & 2.13 & 2.99 & -0.86 \\
\hline
\end{tabular}

\subsection{Sensitivity analysis}

The exact numerical value of the optimal inflation target is conditional on the parameters derived from the calibration strategy of matching statistical moments of the euro area data. To check robustness of these results, we seek to understand how the welfare losses and the optimal inflation target in our baseline model with endogenous growth and DWR differ across parameter calibrations or modelling choices.

Specifically, we analyse the sensitivity of the results to variations of the most relevant parameters of the model affecting (i) the long-term growth and R\&D processes, (ii) the price and wage setting and (iii) the volatility of macro shocks. The sensitivity analysis is designed to change the key parameters in a way to reduce the importance of the endogenous growth and DWR mechanisms - thus tilting our hysteresis-price 
distortions trade-off and going against our main results on the value of the optimal inflation target (see Table 9 in the Appendix for additional sensitivity analyses).

A higher long-term growth rate of the economy (from $1.2 \%$ to $1.6 \%$ ) delivers a higher steady-state nominal wage growth, hence increasing the wage buffer and making DWR less binding. This reduces the negative asymmetric effects from DWR and lowers both the welfare losses and the optimal inflation target (see Table 6, row b).

Higher wage rigidity worsens the model's welfare losses because it increases static and dynamic wage distortions, and amplifies inefficient unemployment fluctuations. However, it also lowers the optimal inflation target because it helps avoiding the occasionally binding wage constraint. Similarly, higher price rigidity makes the welfare costs from price distortions larger and call for a lower inflation target.

Our baseline model features a price setting mechanism à la Rotemberg in which all firms face convex costs of price adjustment with no staggering or price dispersion. To a first order approximation with zero inflation, this is equivalent to the Calvo price setting in which only a share of firms at each point in time can adjust prices. However, at the second order or with trend inflation, the two models differ mainly because there is no price dispersion in the Rotemberg model (see e.g. Ascari and Sbordone (2014)). In particular, the welfare distortions introduced by a higher inflation target increase faster in the Calvo than in the Rotemberg setting. As a consequence, our baseline model with Calvo pricing (with a steady state calibrated to be equivalent to the one with Rotemberg pricing) implies higher welfare losses and call for a slightly lower inflation target (See Table 6, row e).

In a further robustness we relax the degree of DWR, by allowing a certain degree of negative wage inflation (See Table 6, row $\mathrm{f}$ ). This exercise allows us to check the robustness of our results to the tightness of the wage constraint and to account for composition effects and variable wage components. As expected, a lower degree of DWR reduces welfare costs of business cycle fluctations and the optimal inflation rate. Notice, however, that the optimal inflation target is still around $3 \%$ and welfare losses are close to $4 \%$.

Another key aspect pertains to the R\&D process which maps temporary shocks into long-term effects. A reduction in the elasticity of how R\&D affects growth weakens the endogenous growth channel in our model and reduces the hysteresis-distortion trade-off (see Table 6 - row g) implying lower welfare losses and a smaller optimal inflation target.

The volatility of the macroeconomy is also important as it increase the probability of hitting the occasionally binding constraint on nominal wages. It is mostly related to the risk premium shock (see Table 6 row $\mathrm{h}$ ), because demand shocks tend to lower both prices and employment, thus increasing the probability that nominal wages hit the wage bound. The volatility of technology shocks has a lower effect on the optimal inflation rate, because it is much less likely that such shocks lead to the occasionally binding constraint: following a negative technology shock, in fact, 
marginal costs and price inflation tend to increase, thus facilitating the required downward real wage adjustment.

Table 6: Sensitivity analysis

\begin{tabular}{lcc}
\hline Model variation & \multicolumn{2}{c}{ Optimal Welfare Loss } \\
& $\pi^{*}$ & $\pi=\pi^{*}$ \\
\hline a. Baseline calibration & 3.76 & 4.34 \\
\hline Parameter assumptions & & \\
b. Higher growth $(g=1.6)$ & 3.44 & 4.31 \\
c. Higher wage rigidity & 3.52 & 4.41 \\
d. Higher price rigidity & 3.16 & 5.67 \\
e. Calvo pricing & 3.30 & 4.75 \\
f. Lower OBC on DWR $(-1.0 \%)$ & 3.00 & 3.72 \\
g. Lower R\&D diffusion & 3.50 & 3.40 \\
\hline Shock assumptions & & \\
h. Lower risk premium volatility $(\sigma=0.15)$ & 3.06 & 3.05 \\
i. Smaller technology shocks $(\sigma=0.4)$ & 3.68 & 4.12 \\
\hline
\end{tabular}

\section{$6 \quad$ Extensions}

The previous section established the result that accounting for endogenous growth, search frictions and downward wage rigidities in New Keynesian models implies an optimal inflation rate well in excess of the widely applied target of two percent. Next we consider extensions to the model relevant for monetary policy. In the first extension, we study whether the introduction of the zero lower bound on the interest rate has a material effect on our main findings. In a second extension, we discuss three alternative policy rules to evaluate welfare implications from options outside the traditional Taylor-rule inflation targeting framework.

\subsection{Zero Lower Bound}

A common motivation for a higher inflation target, aside from the "greasing the wheels" effect of downward wage rigidities, is the presence of a zero lower bound on interest rates. ${ }^{24} \mathrm{~A}$ large body of recent research has analysed the implications of introducing the ZLB into the standard New Keynesian model for optimal monetary policy and the optimal inflation rate (see, e.g., Coibion et al. (2012), Ascari and Sbordone (2014), Amano and Gnocchi (2020), Andrade et al. (2019)). Most of these papers show that even in the presence of the ZLB, the optimal inflation target is

\footnotetext{
${ }^{24}$ We use the term effective lower bound and zero lower bound interchangeably, but model it as ZLB. Relaxing the lower bound somewhat into negative territory has no effect on our findings.
} 
relatively low, typically below $2 \%$. Even though episodes of ZLB can be very costly, they are infrequent. Price and wage distortions created by higher inflation targets, instead, are small and paid in each period.

To analyse how adding the ZLB on interest rates affects the main results of our analysis, we assume that in normal times monetary policy is given by the same inertial Taylor rule described in equation (11):

$$
R_{t}^{*}=\left(R_{t-1}^{*}\right)^{\varphi_{r}}\left[r\left(\frac{\pi_{t}}{\pi^{*}}\right)^{\varphi_{\pi}}\left(\frac{\hat{Y}_{t}}{\hat{Y}_{s s}}\right)^{\varphi_{y}}\right]^{1-\varphi_{r}} \varepsilon_{t}^{m}
$$

where $R_{t}^{*}$ now denotes the "shadow" or "notional" interest rate that emerges in the absence of the occasionally binding constraint. Since we allow for a ZLB constraint on the nominal interest rate, the dynamics of the actual interest rate are found as:

$$
R_{t}=\max \left\{R_{t}^{*}, 1\right\}
$$

Following Coibion et al. (2012), Andrade et al. (2019) and a large body of recent literature, in this monetary policy rule, today's shadow rate $R_{t}^{*}$ depends on the lagged shadow policy rate, $R_{t-1}^{*}$, rather than the lagged actual rate $R_{t-1}$. This dependence on the lagged notional rate implies that the nominal interest rate remains lower for longer in the aftermath of ZLB episodes. ${ }^{25}$

\begin{tabular}{|c|c|c|c|c|c|c|}
\hline \multirow[t]{2}{*}{ Model variation } & \multirow{2}{*}{$\begin{array}{c}\text { Optimal } \\
\pi^{*}\end{array}$} & \multicolumn{2}{|c|}{ Welfare Loss at } & \multirow{2}{*}{$\begin{array}{c}\Delta \text { Loss } \\
\left(\pi^{*}-1.8\right)\end{array}$} & \multicolumn{2}{|c|}{ Frequency at } \\
\hline & & $\pi=\pi^{*}$ & $\pi=1.8$ & & DWR & ZLB \\
\hline \multicolumn{7}{|l|}{ Exogenous growth model } \\
\hline Benchmark & 0.00 & 0.56 & 0.70 & -0.14 & 0.00 & 0.00 \\
\hline Benchmark with ZLB & 1.72 & 0.84 & 0.84 & -0.00 & 0.00 & 0.08 \\
\hline Benchmark with ZLB \& DWR & 3.24 & 1.22 & 1.39 & -0.17 & 0.20 & 0.04 \\
\hline \multicolumn{7}{|l|}{ Endogenous growth model } \\
\hline Benchmark & 0.00 & 2.16 & 2.53 & -0.37 & 0.00 & 0.00 \\
\hline Benchmark with ZLB & 2.30 & 3.20 & 3.27 & -0.07 & 0.00 & 0.08 \\
\hline Benchmark with ZLB \& DWR & 3.86 & 4.42 & 6.40 & -1.98 & 0.22 & 0.05 \\
\hline Baseline & 3.76 & 4.34 & 6.05 & -1.72 & 0.22 & 0.00 \\
\hline
\end{tabular}

Table 7: Optimal $\pi$ target and welfare: zero lower bound

The table shows the optimal inflation target implied by accounting for the zero lower bound in benchmark and baseline models.

Table 7 provides an overview of how the introduction of the ZLB changes the optimal inflation target and the welfare gains from moving to this target in the exogenous and

\footnotetext{
${ }^{25}$ See also Consolo and Favero (2009); Hills and Nakata (2018) for a discussion on the role of policy inertia.
} 
endogenous growth models, respectively. Consistent with the literature, we find that in our benchmark NK model with exogenous growth, the ZLB causes the optimal inflation target to shift up to 1.7 percent, very close to the widely used target in advanced economies. ${ }^{26}$ The consumption-equivalent welfare loss at this target is less than 1 percent - with the ZLB binding about 8 percent of the time. Augmenting this model with DWR, shifts the optimal inflation target slightly above 3 percent. While the frequency of hitting the ZLB declines due to DWR, it remains beneficial to aim for higher inflation to avoid higher unemployment and lower demand when the wage floor bind. However, welfare gains of moving to the higher inflation target remain limited under exogenous growth as effects are transitory.

Accounting for endogenous growth shifts the optimal inflation target proportionally up compared to their exogenous growth counterpart. This reflects the amplification effect of endogenous growth, which under asymmetries (either due to ZLB, DWR or a combination), translates into lower average growth. While the presence of DWR reduces the frequency of hitting the ZLB, the frequency of being constrained by the wage bound remains unchanged and the average unemployment rate is higher than in the case without DWR. Hence, the optimal inflation target and the corresponding welfare gains are even higher than in our baseline model which does not account for the ZLB.

At the ZLB, our baseline model with endogenous growth and search and matching frictions provides a new perspective on how symmetric wage rigidity and (asymmetric) DWR interact in New Keynesian models compared to models with exogenous growth. In models featuring exogenous growth and no search and matching unemployment (Coibion et al., 2012; Gali, 2013; Amano and Gnocchi, 2020; Billi and Galí, 2020), the limited adjustment in wages (either because of symmetric wage rigidity or DWR) helps reducing downward pressures on marginal labour costs and on price inflation. This reduces the likelihood of hitting the ZLB and helps monetary policy fine tuning the business cycle in the presence of adverse aggregate demand shocks. ${ }^{27}$ In this set of models, higher real wages (because of the lack of wage flexibility) have relatively small effects on long-term output. Also, profitability of firms is not affected in the long-run as the economy is expected to return to the exogenously determined balanced growth path. ${ }^{28}$

\footnotetext{
${ }^{26}$ Our benchmark NK model with exogenous growth differs from the literature mentioned above to the extent it features search and matching frictions. As in Carlsson and Westermark (2016), in our model monetary policy has an effect on the hiring process and unemployment duration. By limiting the degree of monetary policy accommodation, the ZLB increases unemployment hysteresis with persistent effects in the economy.

${ }^{27}$ In Coibion et al. (2012) and Amano and Gnocchi (2020) this calls for a lower inflation target when downward wage rigidities and the ZLB are combined compared to a model which only accounts for the ZLB. We also find that DWR reduce the frequency and severity of zero lower bound episodes, but the optimal inflation target is not reduced by the combined presence of DWR and ZLB in our model due to endogenous growth and search and matching unemployment.

${ }^{28}$ While the deterministic steady-state of the exogenous growth model is not affected by DWR, the ergodic mean of output is slightly affected by the non-linearity introduced by DWR. As such, the ergodic mean of the output gap is negative.
} 
In our model with endogenous growth and search and matching unemployment, instead, the higher real wage dampens job creation by negatively affecting the hiring rate. This leads to larger hysteresis effects on unemployment. Also, limited wage adjustments in the presence of adverse shocks affect the firms' profitability channel ${ }^{29}$ and the value of $R \& D$ and future productivity growth. As such, overall wage rigidity and DWR lead to larger and more persistent effects on unemployment and output growth. However, the welfare effects and the implications for the optimal inflation rate in the economy from these two types of wage rigidities differ. While higher (symmetric) wage rigidity à la Rotemberg decreases the optimal inflation rate of the economy (see Table 9) because it increases the costs of price distortions and compensates the costs from lower output growth, a higher degree of (asymmetric) DWR calls for a higher optimal inflation rate (see Table 5) to minimise the costs of higher unemployment and lower permanent output growth.

\subsection{Alternative Monetary Policy Rules}

Our analysis so far has been conditional on a particular monetary policy rule adopted by the central bank, as captured by the traditional Taylor rule (equation 11). How would different monetary policy strategies affect the relationship between inflation, unemployment and output, and what are the corresponding welfare implications? Alternative monetary policy strategies exist with varying requirements on central bank credibility and commitment to future action. We consider three of them, ordered by their implied extent of change to the current system:

First, we analyse an average inflation targeting strategy which accounts for some undershooting in the past when setting the current interest rate, while leaving the arguments (i.e., output and inflation) in the reaction function unchanged;

$$
R_{t}=\left(R_{t-1}\right)^{\varphi_{r}}\left[r\left(\frac{\pi_{t}^{A}}{\pi^{*}}\right)^{\varphi_{\pi}}\left(\frac{\hat{Y}_{t}}{\hat{Y}_{s s}}\right)^{\varphi_{y}}\right]^{1-\varphi_{r}} \varepsilon_{t}^{m}
$$

where $\ln \pi_{t}^{A}=\frac{1}{16}\left(\sum_{i=1}^{16} \ln \pi_{t-i}\right)$.

Second, we consider a Taylor-rule with the unemployment rate replacing the output term, which we write for convenience in log-form

$$
\log R_{t}=\varphi_{r} \log R_{t-1}+\left(1-\varphi_{r}\right)\left[\log r+\varphi_{\pi} \log \left(\frac{\pi_{t}}{\pi^{*}}\right)+\varphi_{u}\left(u r_{t}-u r_{s s}\right)\right]+\log \varepsilon_{t}^{m}
$$

where $\varphi_{u}=1 / 4$.

Finally, we inspect a price level targeting regime replacing the inflation rate with the price level to fully offset any undershooting of inflation in the past.

$$
R_{t}=\left(R_{t-1}\right)^{\varphi_{r}}\left[r\left(\frac{P_{t}}{\tilde{P}_{t}}\right)^{\varphi_{\pi}^{P L T}}\left(\frac{\hat{Y}_{t}}{\hat{Y}_{s s}}\right)^{\varphi_{y}}\right]^{1-\varphi_{r}} \varepsilon_{t}^{m}
$$

\footnotetext{
${ }^{29}$ We thanks Frank Smets for valuable discussions on this mechanism.
} 
where $\tilde{P}_{t}$ is the price level target and $\varphi_{\pi}^{P L T}=1$ as in one of the exercises of Andrade et al. (2021).

An assessment of the relative costs associated with transitioning from the current to any future policy regime and the likely success of doing so is beyond the scope of this paper. Nevertheless, it is probably save to assume that moving to a price level targeting regime, which relies heavily on credibility about future actions, is more challenging to communicate and implement than changing parameters in the existing policy reaction function. In what follows, we focus entirely on the optimal inflation target and the welfare implications under the three policy options, ignoring issues like inflation expectations' de-anchoring, parameter uncertainty, transition dynamics which can be important in practice.

Table 8: Optimal $\pi$ target and welfare: monetary policy rules

\begin{tabular}{lcccccccc}
\hline Model variation & Optimal & \multicolumn{2}{c}{ Welfare Loss at } & $\Delta$ Loss & \multicolumn{3}{c}{ Statistics at $\pi=1.8$} \\
& $\pi^{*}$ & $\pi=\pi^{*}$ & $\pi=1.8$ & $\left(\pi^{*}-1.8\right)$ & $P(\Delta w=0)$ & $\mu(U R)$ & $\mu(\Delta y)$ \\
\hline Alternative policy & & & & & & & & \\
Average inflation targeting & 3.09 & 4.61 & 5.25 & -0.64 & 0.21 & 9.42 & 1.15 \\
Response to UR & 2.49 & 3.23 & 3.09 & -0.14 & 0.15 & 9.26 & 1.17 \\
Price level targeting & 0.95 & 1.03 & 1.16 & -0.14 & 0.01 & 9.06 & 1.19 \\
\hline Baseline & 3.76 & 4.34 & 6.05 & -1.72 & 0.22 & 9.55 & 1.14 \\
\hline
\end{tabular}

The table shows the optimal inflation target implied by variations to the baseline monetary policy rule specification.

Table 8 reports the optimal inflation target, welfare implications and some descriptive statistics for the different monetary policy options. Average inflation targeting allows for a somewhat lower inflation target compared to the baseline Taylor rule. However, under the optimal inflation target, still close to 3 percent, welfare losses are higher than in the baseline model (4.6 versus 4.3 ), because incomplete interest rate adjustment to prevailing economic conditions not only delay the lift off when exiting recessions, but also limits interest rate cuts when entering them. With a similar delayed policy adjustment during boom phases, this amplifies the business cycle with higher welfare costs. Hence, in our model the gains from moving to an average inflation targeting regime are not evident.

Replacing output by the unemployment rate in the Taylor-rule, instead, allows not only for a lower optimal inflation target (2.5 percent) but also halves the welfare losses compared to the baseline model. This is an immediate result of the lower implied long-term unemployment rate and higher output growth. Both are made possible by allowing the interest rate to respond more directly to asymmetries introduced by DWR, which reduces the frequency of being at the wage floor. ${ }^{30}$

\footnotetext{
${ }^{30}$ The distribution of the unemployment rate, with fat right tails, is more skewed than the distribution of output growth in the model, because the latter can also adjust through other
} 
Finally, price level targeting allows for an inflation target of around 1 percent while reducing welfare losses to the lowest level. By design, this policy option addresses the asymmetry in our model, because the rule implies a proportionate make-up strategy for under- and overshooting episodes when setting the interest rate path. Hitting the wage floor is almost avoided and the average unemployment rate and output growth are almost identical to the calibrated no shock steady-state levels (see Table 2) .

\section{Conclusion}

Central banks in advanced economies pursue a monetary policy framework aimed at achieving an inflation target of about two percent. From a theoretical perspective, the optimal inflation rate in standard New Keynesian models is lower than 2 percent, even accounting for the zero lower bound. These models abstract from an important observation: following severe crises, the level of output can shift permanently below its pre-crisis trend. As a corollary, traditional models imply limited welfare costs of deviating from the optimal inflation target, because policy mistakes can only have transitory, but no permanent effects on output.

We propose an endogenous growth model with downward wage rigidity (DWR) to allow for such dynamics. The inclusion of DWR in a frictional labour market with search and matching unemployment introduces an important non-linearity into the model. This results in asymmetric business cycle fluctuations that resemble those of the plucking theory in which the unemployment rate is characterised by sudden jumps at the start of a recession and slower declines during a recovery. The introduction of endogenous growth allows for the possibility that the resulting aggregate demand shock can have sizeable permanent output effects in the economy. Such effects become even larger if the prevailing economic environment features low inflation and low growth.

The model gives rise to three novel results. First, endogenous growth and DWR combined generate a long-run trade-off between output growth and inflation by transforming temporary symmetric shocks into permanent asymmetric effects on output. Second, this deviation from the monetary policy invariance hypothesis implies significant welfare gains from adopting the optimal inflation target, well in excess of what is implied by standard New Keynesian models. And third, the welfare-maximizing optimal inflation target is more than two percent, for a set of parameter values calibrated for the euro area economy. We find these results robust to plausible variations in parameter values and assumptions of the model.

Our work provides a rationale for revisiting the monetary policy framework in view of the secular trend decline in productivity growth, which have become more en-

factors of production, which are not subject to asymmetric features. 
trenched following the Global Financial Crisis. Increasing the inflation target is one avenue to limit welfare losses in such a context. As shown in an extension, price level targeting could also reduce welfare costs significantly, but would require a shift in the monetary policy framework with new and different challenges. An alternative, possibly simpler policy option, within the inflation targeting framework exists: a shift toward increasing the weight of the unemployment rate in the monetary policy reaction function. This would allow the inflation target to be maintained close to the current 2 percent level while reducing welfare costs substantially. Our model suggests that the unemployment rate can better capture the asymmetry arising from downward wage rigidity. Monetary policy can, by acting directly on the key mechanism leading to hysteresis, lead to non-trivial welfare improvements. 


\section{References}

Abbritti, Mirko, and Stephan Fahr, 2013, Downward wage rigidity and business cycle asymmetries, Journal of Monetary Economics 60, 871-886.

Abbritti, Mirko, and Sebastian Weber, 2019, Market Regulation, Cycles and Growth in a Monetary Union, IMF Working Papers 2019/123, International Monetary Fund.

Acharya, Sushant, Julien Bengui, Keshav Dogra, and Shu Lin Wee, 2021, Slow recoveries and unemployment traps: Monetary policy in a time of hysteresis, $N Y$ Fed Working Paper 831.

Adam, Klaus, and Henning Weber, 2019, Optimal trend inflation, American Economic Review 109, 702-37.

Akerlof, George, William R. Dickens, and George Perry, 1996, The macroeconomics of low inflation, Brookings Papers on Economic Activity 27, 1-76.

Amano, Robert, and Stefano Gnocchi, 2020, Downward Nominal Wage Rigidity Meets the Zero Lower Bound, Journal of Money, Credit and Banking .

Andrade, Philippe, Jordi Gali, Hervé Le Bihan, and Julien Matheron, 2019, The optimal inflation target and the natural rate of interest, Brookings Papers on Economic Activity 173-230.

Andrade, Philippe, Jordi Galí, Hervé Le Bihan, and Julien Matheron, 2021, Should the ECB Adjust its Strategy in the Face of a Lower r*?, CEPR .

Anzoategui, Diego, Diego Comin, Mark Gertler, and Joseba Martinez, 2019, Endogenous technology adoption and $\mathrm{r} \& \mathrm{~d}$ as sources of business cycle persistence, American Economic Journal: Macroeconomics 11, 67-110.

Ascari, Guido, and Argia M. Sbordone, 2014, The macroeconomics of trend inflation, Journal of Economic Literature 52, 679-739.

Barlevy, Gadi, 2004, The cost of business cycles under endogenous growth, American Economic Review 94, 964-990.

Barro, Robert J., 1977, Long-term contracting, sticky prices, and monetary policy, Journal of Monetary Economics 3, 305-316.

Begenau, Juliane, and Juliana Salomao, 2018, Firm Financing over the Business Cycle, The Review of Financial Studies 32, 1235-1274.

Benigno, Gianluca, and Luca Fornaro, 2018, Stagnation Traps, Review of Economic Studies 85, 1425-1470.

Benigno, Pierpaolo, and Luca Antonio Ricci, 2011, The inflation-output trade-off with downward wage rigidities, American Economic Review 101, 1436-66. 
Bernanke, Ben S., 2017, How big a problem is the zero lower bound on interest rates?, Brookings Blog Wednesday, April 12.

Bianchi, Francesco, Howard Kung, and Gonzalo Morales, 2019, Growth, slowdowns, and recoveries, Journal of Monetary Economics 101, 47-63.

Billi, Roberto M., and Jordi Galí, 2020, Gains from wage flexibility and the zero lower bound, Oxford Bulletin of Economics and Statistics 82, 1239-1261.

Blanchard, Olivier, 2018, Should we reject the natural rate hypothesis?, Journal of Economic Perspectives 32, 97-120.

Blanchard, Olivier, and Jordi Galí, 2010, Labor markets and monetary policy: A new keynesian model with unemployment, American Economic Journal: Macroeconomics 2, 1-30.

Blanco, Andrés, Forthcoming, Optimal inflation target in an economy with menu costs and a zero lower bound, American Economic Journal: Macroeconomics .

Cacciatore, Matteo, and Giuseppe Fiori, 2016, The Macroeconomic Effects of Goods and Labor Market Deregulation, Review of Economic Dynamics 20, 1-24.

Carlsson, Mikael, and Andreas Westermark, 2016, Labor market frictions and optimal steady-state inflation, Journal of Monetary Economics 78, 67-79.

Cerra, Valerie, and Sweta Chaman Saxena, 2008, Growth dynamics: The myth of economic recovery, American Economic Review 98, 439-57.

Christoffel, Kai, Keith Kuester, and Tobias Linzert, 2009, The role of labor markets for euro area monetary policy, European Economic Review 53, 908-936.

Coibion, Olivier, Yuriy Gorodnichenko, and Johannes Wieland, 2012, The Optimal Inflation Rate in New Keynesian Models: Should Central Banks Raise Their Inflation Targets in Light of the Zero Lower Bound?, Review of Economic Studies 79, 1371-1406.

Comin, Diego, and Mark Gertler, 2006, Medium-term business cycles, American Economic Review 96, 523-551.

Consolo, Agostino, and Carlo A. Favero, 2009, Monetary policy inertia: More a fiction than a fact?, Journal of Monetary Economics 56, 900-906.

Dickens, William T., Lorenz Goette, Erica L. Groshen, Steinar Holden, Julian Messina, Mark E. Schweitzer, Jarkko Turunen, and Melanie E. Ward, 2007, How wages change: Micro evidence from the international wage flexibility project, Journal of Economic Perspectives 21, 195-214.

Dupraz, Stéphane, Emi Nakamura, and Jón Steinsson, 2019, A Plucking Model of Business Cycles, NBER Working Papers 26351, National Bureau of Economic Research, Inc. 
Eggertsson, Gauti B., and Michael Woodford, 2003, The zero bound on interest rates and optimal monetary policy, Brookings Papers on Economic Activity 2003, $139-211$.

Elsby, Michael W. L., Ryan Michaels, and Gary Solon, 2009, The ins and outs of cyclical unemployment, American Economic Journal: Macroeconomics 1, 84-110.

Faccini, Renato, and Eran Yashiv, 2020, The Importance of Hiring Frictions in Business Cycles, IZA Discussion Papers 12889, Institute of Labor Economics (IZA).

Fahr, Stephan, and Frank Smets, 2010, Downward wage rigidities and optimal monetary policy in a monetary union, The Scandinavian Journal of Economics 112, 812-840.

Ferrando, Annalisa, and Carsten Preuss, 2018, What finance for what investment? survey-based evidence for european companies, Economia Politica 35, 1015-1053.

Friedman, Milton, 1968, The the role of monetary policy, American Economic Review $58,1-17$.

Friedman, Milton, 1993, The "plucking model" of business fluctuations revisited, Economic Inquiry 31, 171-177.

Fujita, Shigeru, and Garey Ramey, 2007, Job matching and propagation, Journal of Economic Dynamics and Control 31, 3671-3698.

Gali, Jordi, 2013, Notes for a new guide to keynes (i): Wages, aggregate demand and employment, Journal of the European Economic Association 11, 973-1003.

Garga, Vaishali, and Sanjay R. Singh, 2020, Output hysteresis and optimal monetary policy, Journal of Monetary Economics .

Gertler, Mark, Luca Sala, and Antonella Trigari, 2008, An Estimated Monetary DSGE Model with Unemployment and Staggered Nominal Wage Bargaining, Journal of Money, Credit and Banking 40, 1713-1764.

Gertler, Mark, and Antonella Trigari, 2009, Unemployment fluctuations with staggered nash wage bargaining, Journal of Political Economy 117, 38-86.

Greenwood, Jeremy, Zvi Hercowitz, and Gregory W. Huffman, 1988, Investment, capacity utilization, and the real business cycle, The American Economic Review $78,402-417$.

Grigsby, John, Erik Hurst, and Ahu Yildirmaz, 2021, Aggregate nominal wage adjustments: New evidence from administrative payroll data, American Economic Review 111, 428-71.

Guerron-Quintana, Pablo A., and Ryo Jinnai, 2019, Financial frictions, trends, and the great recession, Quantitative Economics 10, 735-773. 
Hall, Robert E., 2005, Employment Efficiency and Sticky Wages: Evidence from Flows in the Labor Market, The Review of Economics and Statistics 87, 397-407.

Hall, Robert E., 2011, The long slump, American Economic Review 101, 431-69.

Hall, Robert E., and Thomas J. Sargent, 2018, Short-run and long-run effects of milton friedman's presidential address, Journal of Economic Perspectives 32, 12134 .

Hills, Timothy S., and Taisuke Nakata, 2018, Fiscal Multipliers at the Zero Lower Bound: The Role of Policy Inertia, Journal of Money, Credit and Banking 50, $155-172$.

Holden, Tom, 2016, Computation of solutions to dynamic models with occasionally binding constraints, EconStor Preprints 130143, ZBW - Leibniz Information Centre for Economics.

Holden, Tom D., Paul Levine, and Jonathan M. Swarbrick, 2020, Credit Crunches from Occasionally Binding Bank Borrowing Constraints, Journal of Money, Credit and Banking 52, 549-582.

Justiniano, Alejandro, Giorgio E. Primiceri, and Andrea Tambalotti, 2013, Is there a trade-off between inflation and output stabilization?, American Economic Journal: Macroeconomics 5, 1-31.

Kim, Jinill, and Francisco Ruge-Murcia, 2009, How much inflation is necessary to grease the wheels?, Journal of Monetary Economics 56, 365-377.

Krugman, Paul R., 1998, It's baaack: Japan's slump and the return of the liquidity trap, Brookings Papers on Economic Activity 1998, 137-205.

Kung, Howard, and Lukas Schmid, 2015, Innovation, Growth, and Asset Prices, Journal of Finance 70, 1001-1037.

Lucas, Robert E., 1987, Models of business cycles, Oxford: Blackwell ISBN 9780631147893.

Mankiw, N. Gregory, and Ricardo Reis, 2018, Friedman's presidential address in the evolution of macroeconomic thought, Journal of Economic Perspectives 32, $81-96$.

Moran, Patrick, and Albert Queralto, 2018, Innovation, productivity, and monetary policy, Journal of Monetary Economics 93, 24-41.

Neiss, Katharine S., and Evi Pappa, 2005, Persistence without too much price stickiness: the role of variable factor utilization, Review of Economic Dynamics 8, $231-255$. 
Petrongolo, Barbara, and Christopher A. Pissarides, 2001, Looking into the black box: A survey of the matching function, Journal of Economic Literature 39, 390431.

Phelps, Edmund S., 1967, Phillips curves, expectations of inflation and optimal unemployment over time, Economica 34, 254-281.

Romer, Paul M., 1990, Endogenous technological change, Journal of Political Economy 98, S71-S102.

Rotemberg, Julio J., 1982, Sticky prices in the united states, Journal of Political Economy 90, 1187-1211.

Sala, Luca, Ulf Söderström, and Antonella Trigari, 2012, Structural and Cyclical Forces in the Labor Market During the Great Recession: Cross-Country Evidence, Working Paper Series 264, Sveriges Riksbank (Central Bank of Sweden).

Schmitt-Grohé, Stephanie, and Martín Uribe, 2010, The Optimal Rate of Inflation, in Benjamin M. Friedman, and Michael Woodford, eds., Handbook of Monetary Economics, volume 3 of Handbook of Monetary Economics, chapter 13, 653-722 (Elsevier).

Schmitt-Grohé, Stephanie, and Martín Uribe, 2013, Downward nominal wage rigidity and the case for temporary inflation in the eurozone, The Journal of Economic Perspectives 27, 193-211.

Smets, Frank, and Rafael Wouters, 2007, Shocks and frictions in us business cycles: A bayesian dsge approach, American Economic Review 97, 586-606.

Tobin, James, 1972, Inflation and unemployment, American Economic Review 62, $1-18$.

Yellen, Janet, 2016, The elusive great recovery: Causes and implications for future business cycle dynamics, 60th annual economic conference October 14, 2016, Federal Reserve Bank of Boston. 


\section{A Sensitivity Analysis: Further Robustness Exer- cises}

Table 9 shows additional sensitivity analysis on the optimal inflation target implied by variations to the baseline specification in the model with endogenous growth and downward wage rigidity.

Table 9: Optimal $\pi$ target and welfare: robustness

\begin{tabular}{lcccc}
\hline Model variation & Optimal & \multicolumn{2}{c}{ Welfare Loss at } & $\Delta$ Loss \\
\cline { 3 - 4 } & $\pi^{*}$ & $\pi=\pi^{*}$ & $\pi=1.8$ & $\left(\pi^{*}-1.8\right)$ \\
\hline Parameter assumptions & & & & \\
Higher growth $(g=1.6)$ & 3.44 & 4.31 & 5.44 & -1.13 \\
Higher wage rigidity $\left(\psi_{w}=15\right)$ & 3.52 & 4.41 & 5.81 & -1.39 \\
Higher price rigidity $(\psi=30)$ & 3.16 & 5.67 & 6.69 & -1.02 \\
Calvo pricing & 3.30 & 4.75 & 5.95 & -1.20 \\
Lower OBC $\left(\right.$ min $\left.\left(\pi_{w}\right)=-1 \%\right)$ & 3.00 & 3.72 & 4.21 & -0.49 \\
Price \& wage index $(\varsigma=0.5)$ & 5.40 & 2.68 & 5.92 & -3.24 \\
Lower discount $(\beta=0.995)$ & 3.74 & 2.89 & 3.99 & -1.11 \\
Lower $\varepsilon$ of new patents to R\&D $(0.6)$ & 3.50 & 3.40 & 4.25 & -0.85 \\
\hline Shock assumptions & & & & \\
Small risk premium shocks $(\sigma=0.15)$ & 3.06 & 3.05 & 3.73 & -0.68 \\
Small technology shocks $(\sigma=0.4)$ & 3.68 & 4.12 & 5.69 & -1.58 \\
No monetary policy shocks & 3.66 & 4.13 & 5.69 & -1.56 \\
\hline Model assumptions & & & & \\
Convexity vacancy cost $(\gamma=1.2)$ & 3.66 & 4.81 & 6.49 & -1.68 \\
Fixed capital utilization & 3.68 & 5.16 & 6.82 & -1.66 \\
Fixed capital \& utilization & 3.54 & 4.38 & 5.84 & -1.45 \\
\hline Baseline & 3.76 & 4.34 & 6.05 & -1.72 \\
\hline
\end{tabular}




\section{B Impulse responses: sensitivity to different steady- state growth and inflation rates}

In the last decades, Europe has witnessed a secular decline in average inflation and growth rates (see Table 10). This is relevant because in steady state the rate of growth of nominal wages depends on inflation and output growth. As a consequence, the distance between wage inflation and the lower wage bound depends on both the inflation target and average growth.

Table 10: Key macro variables, percentages

\begin{tabular}{cccc}
\hline & GDP growth & Price Inflation & Nom. Wages \\
\hline 2003 & 2.17 & 1.99 & 4.2 \\
2007 & 2.34 & 1.91 & 4.3 \\
2020 & 1.02 & 1.31 & 2.3 \\
\hline
\end{tabular}

Source: Eurostat. Note: 10-year historical averages

To give an idea of the importance of these factors, Figure 8 presents the impulse responses to a large risk premium shock for different values of steady state inflation and output growth. The figure shows that following a large risk premium shock, a low inflation-low growth environment strongly affects the probability of hitting the lower wage bound and the length and severity of the recessionary episode.

Figure 8: IRFs to a positive risk premium shock
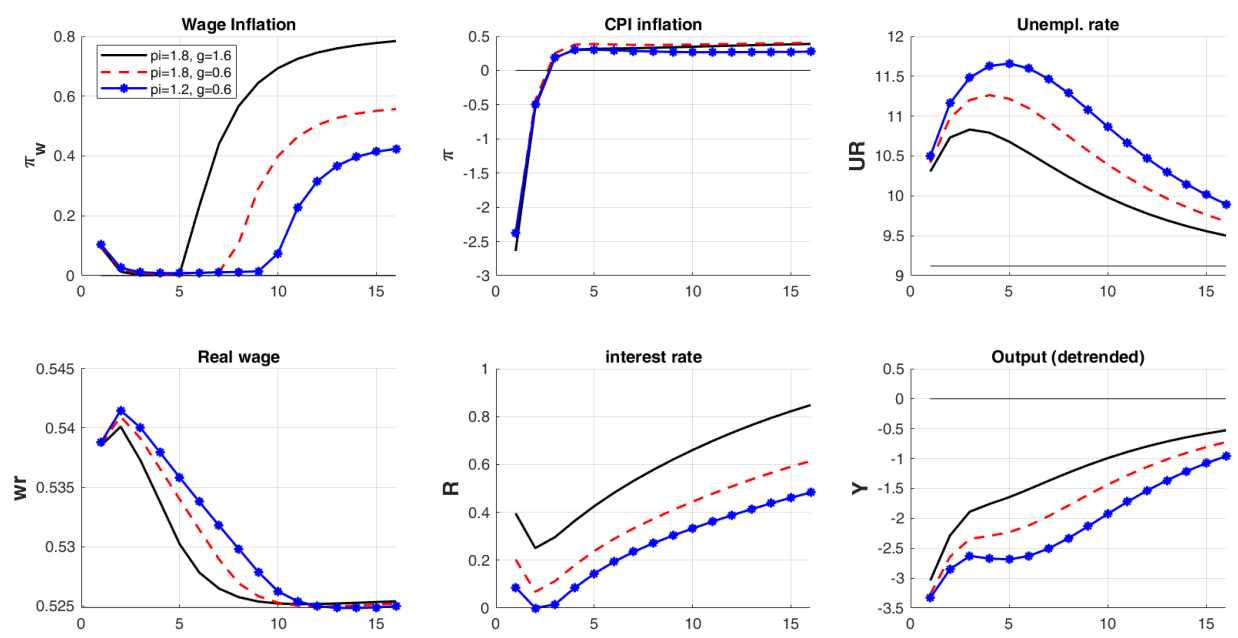


\section{Consumption-equivalent welfare losses}

To further analyze the importance of endogenous growth and DWR for the welfare implications of different inflation targets, Figure 9 shows the implied welfare costs comparing the model with exogenous growth (left panel) and the model with endogenous growth (right panel). As discussed in Section 5, while DWR would call for a higher inflation target even in the model with exogenous growth, the introduction of endogenous growth strongly amplifies the welfare costs of business cycle fluctuations and the welfare costs of choosing a suboptimal inflation target.

Figure 9: Welfare losses from exogenous and endogenous growth models
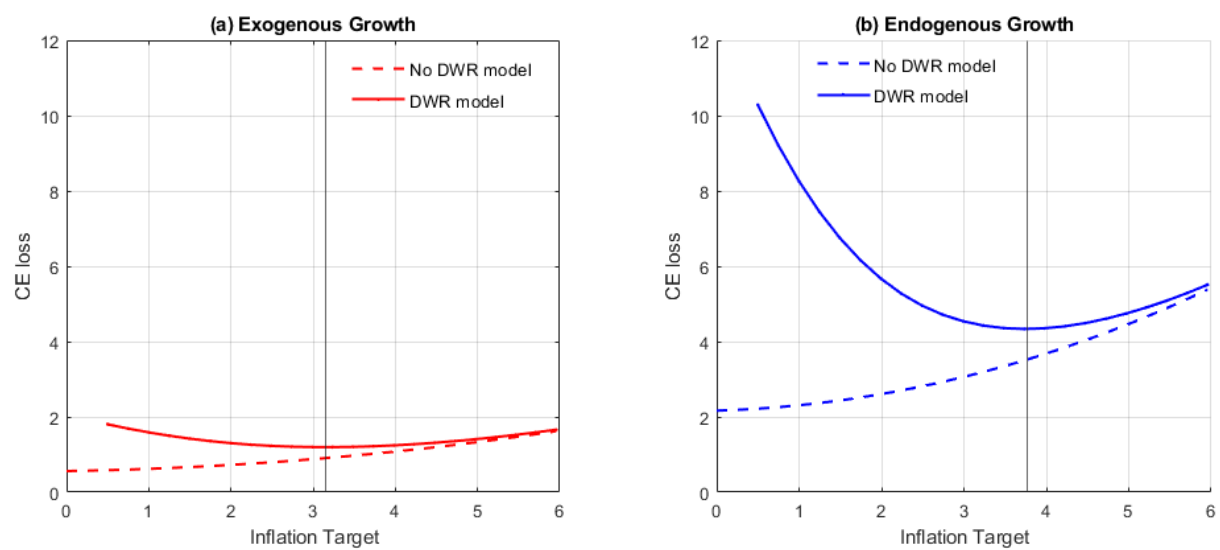

Note: Panel (a) and Panel (b) show consumption-equivalent (CE) welfare losses for different inflation targets in models with exogenous and endogenous growth, respectively. 


\section{Additional moments}

Table 11: Long-run means: different models

\begin{tabular}{lccccc}
\hline & UR & $\Delta y$ & $\Delta T F P$ & $\pi$ & $\pi^{w}$ \\
\hline Steady-state & 9.00 & 1.20 & 0.84 & 1.80 & 3.00 \\
Data & 9.41 & 1.11 & 0.83 & 1.68 & 2.07 \\
Sym. Model - Exo. Growth & 9.19 & 1.20 & 0.84 & 2.04 & 3.23 \\
Sym. Model - End. Growth & 9.15 & 1.18 & 0.82 & 1.88 & 3.05 \\
DWR Model - End. Growth & 9.55 & 1.14 & 0.80 & 2.13 & 3.27
\end{tabular}

The table shows the long run mean (percent, annualized) of selected variables in the steady state of the model, in the euro area data and in baseline and benchmark models.

Table 12: Business cycle moments: different models

\begin{tabular}{|c|c|c|c|c|c|c|c|c|}
\hline \multirow[b]{2}{*}{ Variable $(\mathrm{X})$} & \multicolumn{4}{|c|}{$\sigma(x) / \sigma(y)$} & \multicolumn{4}{|c|}{$\rho(x, y)$} \\
\hline & Data & $\begin{array}{r}\text { Sym } \\
\text { Exo }\end{array}$ & $\begin{array}{c}\text { Sym } \\
\text { Endo }\end{array}$ & $\begin{array}{r}\text { DWR } \\
\text { Endo }\end{array}$ & Data & $\begin{array}{r}\text { Sym } \\
\text { Exo }\end{array}$ & $\begin{array}{c}\text { Sym } \\
\text { Endo }\end{array}$ & $\begin{array}{c}\text { DWR } \\
\text { Endo }\end{array}$ \\
\hline Unemployment & 4.55 & 4.30 & 4.09 & 4.67 & |-0.88 & -0.65 & -0.68 & -0.69 \\
\hline Employment & 0.52 & 0.43 & 0.41 & 0.52 & 0.83 & 0.66 & 0.69 & 0.68 \\
\hline Investment & 2.34 & 3.22 & 2.22 & 2.34 & 0.86 & 0.93 & 0.88 & 0.88 \\
\hline Consumption & 0.55 & 0.48 & 0.48 & 0.47 & 0.84 & 0.88 & 0.89 & 0.90 \\
\hline TFP & 0.79 & 0.85 & 0.84 & 0.81 & 0.97 & 0.96 & 0.97 & 0.95 \\
\hline Nominal wages & 0.16 & 0.60 & 0.57 & 0.46 & 0.31 & 0.61 & 0.68 & 0.63 \\
\hline Prices & 0.50 & 0.90 & 0.86 & 0.80 & 0.21 & 0.54 & 0.58 & 0.53 \\
\hline Real wages & 0.46 & 0.64 & 0.60 & 0.73 & -0.13 & 0.17 & 0.09 & -0.08 \\
\hline$\sigma(y)$ & 1.20 & 1.06 & 1.16 & 1.20 & & & & \\
\hline
\end{tabular}

The table shows the HP(1600)-filtered second moments of selected variables in the euro area data and in the baseline and benchmark models. 